\title{
Shear response of carbon fiber composite octet-truss lattice structures
}

\author{
Liang Dong ${ }^{1}$ and Haydn Wadley \\ Department of Materials Science and Engineering, \\ University of Virginia, Charlottesville, Virginia 22903
}

\begin{abstract}
Ultralight three dimensional space filling octet-truss lattice structures have been fabricated from carbon fiber reinforced polymer (CFRP) laminates using a mechanical snapfitting and adhesive bonding technique. The lattice structures moduli and strengths have been measured during (001) in-plane shear as a function of the lattice relative density $(\bar{\rho})$. Their strength was determined by the activation of two strut failure modes: elastic buckling of the struts governed the response when $\bar{\rho}<5 \%$, while delamination failure controlled the strength for $16 \%>\bar{\rho}>5 \%$. The measured shear strengths are shown to be well predicted by micromechanics models based on the elastic buckling and delamination failure of the struts. Snap-fit CFRP octet-truss lattice structures with densities of $24-230 \mathrm{kgm}^{-3}$ are found to have mechanical properties superior to polymer and metal foams, and are competitive with Balsa wood and recently reported Ti-6Al-4V octet-truss lattices. They provide new opportunities for ultra-lightweight multi-axially loaded structures.
\end{abstract}

Keywords: Octet-truss lattice, Elastic stiffness, Strength, Carbon fiber composite

\footnotetext{
${ }^{1}$ Corresponding author: ld5fy@ virginia.edu

(C) 2015. This manuscript version is made available under the Elsevier user license http://www.elsevier.com/open-access/userlicense/1.0/
} 


\section{Introduction}

Cellular lattice structures have attracted considerable interest for the cores of lightweight sandwich panels $[1,2,3]$. In this approach, two thin face sheets made from materials with high specific stiffness and strength are widely separated by a low density lattice core $[4,5,6]$. The mechanical performance of a sandwich panel is governed by its geometry (face sheet thickness and core height) and by the mechanical properties of its faces and core with the latter governed by the core topology and properties of the materials used to make it. In addition to their significant bend resistance, some sandwich panel structures also provide substantial out of plane compressive strength $[7,8,9,10,11,12,13,14,15]$, and have attracted interest for mitigating the effects of impulsively applied loads $[16,17,18,19,20,21]$.

Lattice topology core structures with pyramidal and tetrahedral cell topologies [3] have been developed to promote truss deformation in a stretch dominated manner [22], whereupon the stiffness and strength scale linearly with relative density, $\bar{\rho}$, of the lattice structure (the density of the lattice structure divided by that of the material from which it was made) $[4,5,23]$. The use of high specific stiffness carbon fiber reinforced polymer (CFRP) laminates to make sandwich panel structures using single layer pyramidal lattice has been explored recently [11,12,13,14,24]. These studies indicate their mechanical properties are competitive with existing materials and topologies. However, as the thickness of a core is increased to improve the bending resistance of a sandwich panel, the distance of nodal connections between the core and the faces (which scale with depth for single unit cell thick cores) also increases $[9,18,25,26]$. This then increases the susceptibility of the panel to face sheet wrinkling [27,28] and nodal failure [28] during panel bending. Furthermore, as the relative density of such a lattice is decreased to enable more of the panel mass to be allocated to faces, the trusses become more, slender resulting in failure by 
elastic buckling $[29,30]$. These considerations have led to an interest in the multilayer lattice structures whose cell size can be defined independently of the sandwich core thickness.

The octet-truss [31] lattice structure, Figure 1 with face-centered cubic symmetry, provides a method for filling 3-D space with a structurally efficient truss structure of arbitrary cell size. The joint connectivity of the octet truss is 12 , and the trusses of this spatially periodic material deform by local stretching for all macroscopic loading states [32]. The effective mechanical properties of the stretch-dominated octet-truss lattice have been analyzed using a micromechanics approach [32], and shown to have an almost isotropic yield surface. When made from high specific strength materials, the octet-truss lattice is a highly weight efficient, multiaxial stress supporting structure. Lightweight aluminum alloy structures have been made by an investment casting [32] and by additive manufacturing methods [33,34,35]. Wrought titanium alloy octet-truss lattices have also been recently fabricated [36] via a combined snap-fit and brazing approach, and offer potential for elevated temperature aerospace applications.

Carbon fiber composites (CFRP) have a higher specific strength and stiffness than aluminum and titanium alloys, and are therefore a promising material for making stiff and potentially strong cellular structures for ambient temperature, lightweight applications. The application of a simple "snap-fit" assembly method [10] for fabricating and joining the pyramidal trusses and intermediate faces of an octet-truss cellular material made from CFRP laminates has been recent described [14]. The compressive responses of the octet-truss lattice in both its [001] and [100] directions were characterized as a function of the lattice relative density. However, sandwich panels are most widely used in situations where they are subjected to significant bending; a loading mode in which the shear response of the core governs the panel's mechanical response [1,2]. Here, the in-plane shear of snap-fit CFRP octet-truss lattices has been 
experimentally investigated as a function of the lattice relative density and their stiffness and strength compared to micromechanical predictions.

\section{CFRP lattice fabrication}

\subsection{Composite laminate materials}

CFRP laminates with a 0/90 architecture were procured from McMaster-Carr and used to make the octet-truss lattice structures using a snap-fit method. The laminate sheets had a thickness $t=1.59 \mathrm{~mm}$ and had a $55 \%$ by volume carbon fibers. The carbon fibers have a Young's modulus of $228 \mathrm{GPa}(33 \mathrm{Msi})$ and were dispersed in a vinyl ester matrix. The density of the laminate material was $1,440 \mathrm{~kg} / \mathrm{m}^{3}$. The laminate was comprised of 8 plies: the 2 surface plies were made from plain weave fabrics while the 6 unidirectional interior plies of the same thickness were laid up in a $[0 / 90 / 0]$ s arrangement, Fig. 2. The plain weave fabric layers contained fibers oriented along the two in-plane axes, and once cured could support flexural and tensile loads applied on multiple axes [20]. The woven laminates are also less sensitive to local damage compared with unidirectional laminates, and reduced the susceptibility to delamination during cutting operations [20]. Laminate sheets with woven plies on the outer surfaces were thus selected for the present study based upon this manufacturing constraint: the need to minimize the risk of delamination failures during fabrication and assembly of the lattice structures. Octet-truss lattices made from laminates with quasi-isotropic stacking sequence would be very interesting and a ripe area for future studies as it simplifies analysis of the laminate responses.

Experimental $[11,12,15]$ and more fundamental studies $[37,38,39,40]$ have shown that the compressive strengths of woven laminates are lower than unidirectional laminates due to fiber waviness. It is noted that the as-received laminate sheets contained two plain weave fabrics, four 
$0^{\circ}$ unidirectional plies and two $90^{\circ}$ unidirectional plies. Such a microstructure indicates that the as-received laminate sheets will be orthotropic rather than the transversely isotropic material often encountered in the simpler 0/90 balanced laminates.

The composite laminate materials were tested in uniaxial compression along the two unidirectional fiber directions in order to determine the longitudinal and transverse compressive and tensile moduli and strengths of the parent material used to manufacture the octet-truss lattices. A nominal applied strain rate of $10^{-4} \mathrm{~s}^{-1}$ was employed in these tests. Unclamped compression tests were conducted with stocky (to prevent elastic buckling) dog-bone shaped laminate specimens [14] compressed between two flat, parallel and rigid platens with no end clamping. Celanese compression (CLC) tests were also conducted in which the longitudinal splitting and delamination can be suppressed. The mechanical properties of the as-received CFRP laminate along both the longitudinal and transverse directions are summarized in Table 1. The laminate exhibited a substantial amount scattering in compressive strength; this well-known phenomenon [41] has been attributed to the complex distribution of damage zones (induced by internal flaws or stress concentrations) which create instabilities that prematurely trigger kink band formation.

The laminate compressive strengths differ in different loading conditions due to different failure mechanisms: in CLC compression, failure was controlled by plastic fiber micro-buckling, whereas the failure was dominated by delamination in unclamped compression, as observed optically (Fig. 3(a) and (b)) and confirmed by $\mu$-XCT analysis (Fig. 3(c) and (d)). The damage modes (kink bands and delamination) were both initiated within the plain weave surface plies where fiber misalignment was the greatest. This initial damage can disturb the subsequent loading condition in unclamped compression by introducing bending moments at the specimen 

damage zones prior to plastic fiber micro-buckling of the interior unidirectional plies. This could also lead to progressive damage as different interior unidirectional plies would fail at different times. The unclamped compression usually failed by a delamination mechanism rather than the plastic fiber micro-buckling of all the unidirectional plies when the peak stress in the stress-strain diagram was attained. In contrast, the CLC test fixture eliminated the end effects, allowing the interior unidirectional plies along the loading direction to fail simultaneously and thus fully contribute the plastic fiber micro-buckling strength, and resulted in a higher compressive strength. For the sake of simplicity, we denote the failure mode represented by that observed in the unclamped compression as "delamination dominate failure", and that represented by the failure mode observed in the CLC compression as "plastic fiber micro-buckling failure". It will be seen that the unclamped compression best simulated the loading condition of the compressively loaded octet struts of the shear samples.

\subsection{Lattice fabrication}

The CFRP octet-truss lattice structures were manufactured from the as-received CFRP laminate sheets. The fabrication route is summarized in Fig. 4. The pyramidal truss row patterns, Fig. 4(a), and intermediate faces, Fig. 4(b), were water jet and CNC mill cut separately from the laminate sheets. The strut axis was chosen to be parallel to either the laminates longitudinal or transverse directions (half the fibers were therefore aligned with the struts axes). The terms "longitudinal strut" and "transverse strut" are subsequently used to denote octet struts with axes parallel to the longitudinal and transverse directions of the laminate sheet from which they were cut. A recently reported "snap-fit" assembly route [36] was employed here to assemble the octettruss lattice: the pyramidal trusses patterns were snap-fitted into each other to produce pyramidal 
truss layers, and then counter-sunk into the intermediate faces to a depth of half the laminate thickness using cruciform shaped slots to form the octet-truss lattice. The assembled structure was bonded using $\mathrm{HYSOL}^{\circledR} \mathrm{E}-120 \mathrm{HP}^{\mathrm{TM}}$ (Loctite ${ }^{\circledR}$ Brand, Westlakes, OH) [42] high strength epoxy applied to the nodal regions. The epoxy was cured at $60^{\circ} \mathrm{C}$ for 12 hours. This epoxy had a higher lap shear strength than the laminate matrix vinyl ester (20MPa). Samples with square cross section struts (side $t$, equals to laminate sheet thickness) of various lengths, $l$, defined in Fig. 5(a) were fabricated to enable study of the strut slenderness upon mechanical response. The geometric parameters defining each of the test structures are summarized in Table 2.

In order to facilitate gripping in a shear test fixture, solid external face sheets were fabricated with cross-shaped slots milled into them at appropriate locations such that the pyramidal nodes of the octet-truss cores could be snap-fit into these solid face sheets. Photographs of the shear samples are shown in Fig. 6 during their assembly process so that the orientation of the trusses can be seen.

\subsection{Relative density}

A schematic illustration of the two types of trusses (pyramidal and intermediate face) and the snap-fit octahedral cell are shown in Fig. 5 together with a coordinate system. The figures define all the relevant geometric parameters of the structure. The struts have square cross section, $t=w, \omega=45^{\circ}$. By calculating the volumes of the regions occupied by material and scaling this by the unit cell volume, the relative density, $\bar{\rho}$ of the octahedral cell is given by

$$
\bar{\rho}=\frac{6 \sqrt{2} l t^{2}+\left(K_{1}-K_{2} t+2 \sqrt{2} t^{2}\right) t}{\left(l+K_{3}\right)\left(l+K_{4}\right)^{2}}
$$

where the geometric parameters are defined (using Fig. 5) as,

$$
\begin{aligned}
& K_{1}=\sqrt{2}(b+2 m)^{2}+2 \sqrt{2} h(b+c)+4 \sqrt{2} b h_{\mathrm{tab}} \\
& K_{2}=(2 \sqrt{2}+2) b-2 c+2 \sqrt{2}\left(h+h_{\mathrm{tab}}\right)+8 m
\end{aligned}
$$




$$
\begin{aligned}
& K_{3}=\sqrt{2}\left(h+2 h_{\mathrm{tab}}\right) \\
& K_{4}=\frac{\sqrt{2}}{2}(b+c)
\end{aligned}
$$

Equation (1) was arranged to identify the separate volume contributions from the trusses (first term of the numerator) and the nodes. Further simplification was achieved by introducing non-dimensional lengths; $\bar{t}=t / l, \bar{b}=b / l, \bar{c}=c / l, \bar{h}_{t a b}=h_{\mathrm{tab}} / l, \bar{h}=h / l$ and $\bar{m}=m / l$. As a result, $\overline{K_{1}}=K_{1} / l^{2}, \overline{K_{2}}=K_{2} / l, \overline{K_{3}}=K_{3} / l$, and $\overline{K_{4}}=K_{4} / l$, whereupon;

$$
\bar{\rho}=\frac{6 \sqrt{2} \bar{t}^{2}+\left(\overline{K_{1}}-\overline{K_{2}} \bar{t}+2 \sqrt{2} \bar{t}^{2}\right) \bar{t}}{\left(1+\overline{K_{3}}\right)\left(1+\overline{K_{4}}\right)^{2}}
$$

Octet-truss lattice structures were fabricated with a relative densities ranging from 1.7 to $\sim 16 \%$ by allowing the strut length $l$ to vary between 8 and $33 \mathrm{~mm}$.

\section{Experimental shear responses}

The CFRP octet-truss lattices were tested at ambient temperature in (001) in-plane shear at a nominal strain rate of $3 \times 10^{-4} \mathrm{~s}^{-1}$ in accordance with ASTM standards C273. The ASTM C273 standard specifies use of a compression shear plate configuration and a length to thickness ratio of the panel larger than 12:1; however, a subsequent analysis has shown that a smaller length to thickness ratio is acceptable for this type of testing [43]. The shear samples used here had a length to thickness ratio of 4:1. The experimental setup is shown in Fig. 7. In order to attach the shear testing samples to the test fixture, holes were drilled into the composite face sheets of the shear panels and the panels attached to the test fixture. The measured load cell force was used to calculate the stresses applied to the structure. The sample side length, $L(\mathrm{~s})$ was defined using Fig. 6(b), as the distances between the left-and-right edges defined by the pyramidal trusses, while 
sample height, $H(\mathrm{~s})$ was the distances between the top-and-bottom edges defined by the shear plates, Fig. 6(a). The volume occupied by the extra edge nodes could be trimmed off if necessary without changing the mechanical response and was therefore neglected. The loading direction is shown in Fig. 6(a). A laser extensometer measured the displacements of the shear plates and the shear strain was then deduced. Unload-reload cycles were used prior to the onset of peak stress in order to determine the elastic stiffness of the specimens.

The (001) in-plane shear stress-strain responses of the CFRP octet-lattice shear samples loaded in the $\alpha=0^{\circ}$ direction are shown in Fig. 8. In all cases, an initial linear stress-strain response was observed, followed by a regime of non-linear behavior. The stress progressively decreased with increasing strain after the attainment of peak shear stress associated with a series of strut damage. Photographs taken periodically during loading indicated that the lowest relative density sample ( $\bar{\rho}=1.7 \%$ ) failed by elastic buckling of the out of plane struts, Fig. 9(d). Samples of higher densities failed by delamination dominated failure (the same failure mode as observed in the unclamped compression discussed in Section 2.1) of the compressed $0^{\circ}$ fiber ply-oriented pyramidal trusses, Fig 9(b) and (c), at the peak stress. Delamination of some of the compressed $0^{\circ}$ ply-oriented pyramidal trusses at the ends of shear samples was observed prior to the attainment of peak stress. This phenomenon was a manifestation of the compressive loading component of the ASTM C273 test method. Continued loading resulted in fracture of tensile struts near the sample ends and intermediate face delamination at some nodes. Shear fracture was observed in the $90^{\circ}$ ply-oriented pyramidal truss struts near the ends due to induced bending moments at the nodes as the core continued to deform after the attainment of peak stress, Fig. 9(a). Table 3 provides a summary of the shear moduli and strengths of the samples. 


\section{Micromechanics model}

The effective mechanical properties of an ideal octet-truss lattice material (in the limit of vanishing node volume) have been investigated by Deshpande, Fleck and Ashby [32]. This DFA model analyzed an ideal octahedral cell with cubic symmetry, made from isotropic materials, and the results apply to the octet-truss lattice constructed by the 3-D stacking of such an octahedral cell. The DFA model assumed pin-joined struts to simplify the analysis since for small $t / l$, the contribution to overall stiffness of the octet-truss lattice from bending of the struts is negligible compared to that from stretching. The analysis here of lattices made from an orthotropic symmetry laminate material utilizes the same assumption.

The snap-fit octahedral cell contains extra nodal masses, Fig. 5(c), and therefore has a transverse isotropic symmetry due to the nodal geometry. The components of the linear elastic stress, $\sigma$ and strain, $\varepsilon$ tensor of a transversely isotropic material takes the form (with Cartesian indices);

$$
\left[\begin{array}{l}
\sigma_{x x} \\
\sigma_{y y} \\
\sigma_{z z} \\
\sigma_{y z} \\
\sigma_{x z} \\
\sigma_{x y}
\end{array}\right]=\left[\begin{array}{cccccc}
C_{x x x x} & C_{x x y y} & C_{x x z z} & 0 & 0 & 0 \\
C_{x x y y} & C_{x x x x} & C_{x x z z} & 0 & 0 & 0 \\
C_{x x z z} & C_{x x z z} & C_{z z z z} & 0 & 0 & 0 \\
0 & 0 & 0 & C_{y z y z} & 0 & 0 \\
0 & 0 & 0 & 0 & C_{y z y z} & 0 \\
0 & 0 & 0 & 0 & 0 & \frac{c_{x x x x}-C_{x x y y}}{2}
\end{array}\right]\left[\begin{array}{c}
\varepsilon_{x x} \\
\varepsilon_{y y} \\
\varepsilon_{z z} \\
\varepsilon_{y z} \\
\varepsilon_{x z} \\
\varepsilon_{x y}
\end{array}\right]
$$

with the principal material axes $(x, y, z)$ are defined in Fig. 5(c). There are five independent elastic stiffness constants, denoted $C_{i j}$ (using contracted indices $i$ and $j$ for ordered pairs of Cartesian indices), the set $\left\{C_{x x x x}, C_{x x y y}, C_{x x z z}, C_{z z z z}, C_{y z y z}\right\}$ is equivalent to $\left\{C_{11}, C_{12}, C_{13}, C_{33}, C_{44}\right\}$ using contracted indices. $C_{z z z z}$ can be determined from the elastic region in the stress-strain diagram $\left(\sigma_{z z}\right.$ versus $\left.\varepsilon_{z z}\right)$ of the [001] direction confined compression $\left(\varepsilon_{x x}=\right.$ $\varepsilon_{y y}=0$ ), and $C_{x x x x}$ from that ( $\sigma_{x x}$ vs. $\left.\varepsilon_{x x}\right)$ of the [100] direction confined compression ( $\varepsilon_{y y}=$ 
$\varepsilon_{z z}=0$ ). $C_{y z y z}$ can be determined from the elastic region in the stress-strain diagram ( $\sigma_{y z}$ vs. $\varepsilon_{y z}$, or $\sigma_{x z}$ vs. $\left.\varepsilon_{x z}\right)$ of the (001) in-plane shear, and $\left(C_{x x x x}-C_{x x y y}\right) / 2$ from that $\left(\sigma_{x y}\right.$ vs. $\left.\varepsilon_{x y}\right)$ of the (100) in-plane shear; $C_{x x y y}$ can thus be determined if $C_{x x x x}$ is known from the [100] direction confined compression. $C_{x x z z}$ can be determined in the [001] direction free compression after $C_{z z z z}$ is determined from the [001] direction confined compression by referring to the elastic region in the stress-strain diagram of $\left(\sigma_{z z}-C_{z z z z} \varepsilon_{z z}\right) / 2$ versus the lateral strain $\varepsilon_{x x}$ or $\varepsilon_{y y}$. In the present study, (001) in-plane shear determines the elastic constant, $C_{y z y z}$ (i.e., $\left.C_{44}\right)$.

\section{1. (001) in-plane shear}

It is noted here that the top and bottom pyramidal trusses of an octahedral cell, Fig. 5(c), exhibits mirror symmetry about the intermediate face. The (001) in-plane shear response is therefore independent of the sign of shear loading angle $\alpha$. The (001) in-plane shear modulus for a unit cell depends on both the longitudinal and transverse struts compressive moduli as there will be identical numbers of longitudinal and transverse compression struts when the unit cell is subjected to (001) in-plane shear. The (001) in-plane shear strength, however, will be governed by the transverse struts compressive strength.

Since the laminate material is orthotropic rather than transversely isotropic, the longitudinal struts have higher tensile and compressive moduli than the transverse struts. The longitudinal and transverse struts will therefore suffer different displacements when the octahedral cell is loaded in shear, and static equilibrium is achieved by (compensating) nonuniform nodal displacements. To simplify the analysis, we treat the pyramidal strut as isotropic with an axial modulus, $E_{S}=E_{C}^{\text {ave }}$ where $E_{C}^{\text {ave }}\left(=\frac{1}{2}\left(E_{C}^{L}+E_{C}^{T}\right) \sim 26 \mathrm{GPa}\right.$, with $E_{C}^{L}=$ 32.5GPa, and $E_{C}^{T}=19.8 \mathrm{GPa}$, see Table 1 ) is the average of longitudinal and transverse struts compressive moduli. Such an assumption implies that the pyramidal struts that are tension 
develop the same strain as the compression pyramidal struts when the lattice is in shear. In reality, however, the node regions near the ends of tension pyramidal struts take on the majority of tensile deformation as these node regions support tensile loads at $45^{\circ}$ to the fiber directions, and the laminate has a low tensile stiffness and strength at $45^{\circ}$ to the fiber directions [14]. We note that fortunately the laminate has a large ultimate strain $(\sim 0.12)$, a $45^{\circ}$ tensile modulus of $\sim$ $18 \mathrm{GPa}$, and a $45^{\circ}$ ultimate tensile strength of $\sim 200 \mathrm{MPa}$ [14]. These values are comparable to the transverse strut compressive modulus and delamination strength. Therefore, while the following analysis is a first order approximation, it is subsequently found sufficient to predict the shear responses of the snap-fit lattices.

The (001) in-plane shear strength depends on the shear loading direction in this plane.

The present study used $\alpha=0^{\circ}$, the measured shear strength $\tau_{0^{\circ}}^{p k}$ is therefore $\tau_{\mathrm{zx}}^{p k}$, with the principal axes defined in Fig. 10(a).

\subsubsection{Shear modulus}

Consider the octahedral cell in Fig. 10(a) with an in-plane shear displacement $\delta^{\prime}$ applied to the top node of the cell in the direction defined by an angle $\alpha\left(0^{\circ} \leq \alpha \leq 45^{\circ}\right.$, due to symmetry). Such a displacement can be resolved into two perpendicular components;

$$
\delta_{1}^{\prime}=\delta^{\prime} \cos \alpha
$$

and

$$
\delta_{2}^{\prime}=\delta^{\prime} \sin \alpha
$$

Fig. 10(b) shows the free body diagram of the edge clamped strut highlighted in Fig. 10(a) with length $l$ and side $t$ when the octahedral cell is in shear. Symmetry dictates that displacements and rotations of nodes apart from the top and bottom shown in Fig. 10(a) are constrained. The axial 
and shear displacements applied to the strut within the plane parallel to the $\delta_{1}{ }^{\prime}$ direction (i.e. $x$ direction) are;

$$
\delta_{a}^{\prime}=\delta_{1}^{\prime} \cos \omega
$$

and

$$
\delta_{s}^{\prime}=\delta_{1}^{\prime} \sin \omega
$$

with such a strut subjected to either compression or tensile displacement. From beam theory, the axial and shear forces in such a strut are given by

$$
F_{\mathrm{A}}^{\prime}=E_{C}^{a v e} t^{2} \frac{\delta_{1}^{\prime} \cos \omega}{l}
$$

and

$$
F_{S}^{\prime}=\frac{12 E_{C}^{a v e} I \delta_{1}^{\prime} \sin \omega}{l^{3}}
$$

The total force applied along the $\delta_{1}^{\prime}$ direction of a unit cell is

$$
F_{1}^{\prime}=2\left(F_{\mathrm{A}}^{\prime} \cos \omega+F_{\mathrm{S}}^{\prime} \sin \omega\right)=\frac{E_{C}^{a v e} t^{2} \delta_{1}^{\prime}}{l}\left[1+\left(\frac{t}{l}\right)^{2}\right]
$$

The force applied along the $\delta_{2}^{\prime}$ direction is;

$$
F_{2}^{\prime}=2\left(F_{\mathrm{A}}^{\prime} \cos \omega+F_{\mathrm{S}}^{\prime} \sin \omega\right)=\frac{E_{C}^{\text {ave }} t^{2} \delta_{2}^{\prime}}{l}\left[1+\left(\frac{t}{l}\right)^{2}\right]
$$

It is noted that Equation (7) was derived assuming fixed-end (built-in) struts $(k=2)$; for pin-joined struts $(k=1)$, the contribution to the stiffness by bending of the struts is negligible, and the $(t / l)^{2}$ terms (i.e., $F_{\mathrm{S}}^{\prime}$ terms) in Equation (7) disappear. The total shear force, $F^{\prime}$, applied on the unit cell is then

$$
F^{\prime}=\sqrt{\left(F_{1}^{\prime}\right)^{2}+\left(F_{2}^{\prime}\right)^{2}}=\frac{E_{C}^{a v e} t^{2} \delta^{\prime}}{l}
$$

The total shear stress applied to the octahedral cell is thus

$$
\tau=\frac{F^{\prime}}{A_{[001]}}=\frac{E_{C}^{a v e} t^{2} \delta^{\prime}}{A_{[001]}}
$$


The shear strain

$$
\gamma=\frac{2 \delta^{\prime}}{H_{[001]}}
$$

Therefore, the shear modulus of the octahedral cell is

$$
G=\frac{\tau}{\gamma}=\frac{t^{2} H_{[001]}}{2 A_{[001]} l} E_{C}^{a v e}
$$

If we define $E_{S}=E_{C}^{a v e}(26 \mathrm{GPa})$, Equation (11) can be expressed in the form of relative shear modulus;

$$
\frac{G}{E_{S}}=\frac{t^{2} H_{[001]}}{2 A_{[001]} l}=K_{G} \frac{t^{2} H_{[001]}}{l A_{[001]}}
$$

with $K_{G}=\frac{1}{2}$.

\subsubsection{Shear strength}

Equation (9) represents the total shear stress applied to the unit cell during (001) in-plane shear. The axial stress, $\sigma_{A}$, in a pyramidal strut is given by

$$
\sigma_{A}=\frac{E_{C}^{a v e} \delta^{\prime} \cos \alpha}{\sqrt{2} l}
$$

Therefore, the (001) in-plane shear stress applied to the octahedral cell, $\tau$, can be expressed in terms of the axial stress, $\sigma_{A}$;

$$
\tau=\sigma_{A} \frac{\sqrt{2} t^{2}}{A \cos \alpha}
$$

A pyramidal strut can support compressive load until its collapse strength $\sigma_{c}$ is achieved. Therefore, the octahedral cell shear strength is given by

$$
\tau_{p k}=\sigma_{c} \frac{\sqrt{2} t^{2}}{A \cos \alpha}
$$


This shear strength depends upon the specific failure mechanism (elastic buckling, delamination or plastic fiber micro-buckling) of the composite struts, and is obtained by replacing $\sigma_{c}$ in Equation (15) with the corresponding compressive strength of the composite strut. We note that since the polymer matrices of fiber composites used here have quite low shear strengths, elastic fiber micro-buckling is not an operative failure mode and has not been considered in the collapse analysis below [44]. A compressed CFRP strut can therefore collapse by either (i) elastic buckling, (ii) delamination or (iii) plastic fiber micro-buckling.

At low densities, struts are slender enough to collapse by elastic buckling. The compressive strength of the lattice can be obtained by replacing, $\sigma_{\mathrm{c}}$ in Equation (15), with the elastic buckling stress, $\sigma_{\mathrm{E}}$ for a solid strut with square cross section of side $t$;

$$
\sigma_{\mathrm{E}}=\frac{k^{2} \pi^{2} E_{C}^{a v e}}{12}\left(\frac{t}{l}\right)^{2}
$$

The factor $k$ is determined by the end conditions of the buckling struts. The pin-jointed $k=1$ condition is assumed here for consistency with the DFA model [32].

For a stubby composite strut in compression, the compressive loads accentuate shear stresses developed around initial defects such as misaligned or wavy fibers, matrix pores, partial delaminations, or residual stresses, leading to the formation of damage zones which propagate at an inclined angle to the loading direction [41]. For a matrix with low shear strength, delamination at the inter-ply interface can be initiated within such damage zones [41]. The lattice strength controlled by strut delamination is obtained by replacing $\sigma_{\mathrm{c}}$ in Equation (15) with the measured delamination strength, $\sigma_{d l}$. The lattice strength depends on the strut with highest flaw density or stress concentration. Therefore, a conservative transverse compressive strength of the laminate material governed by delamination $\left(\sigma_{d l}^{T}(\mathrm{~min})=240 \mathrm{MPa}\right.$, Table 1$)$ was used for the model predictions. 
For a stubby composite strut with a strong matrix shear strength, the interface debonding can be prevented after the formation of damage zones. The composite struts then fail by plastic fiber micro-buckling once the matrix plastically yields. The plastic fiber micro-buckling stress, $\sigma_{m b}$, is given by the CLC compression measurement. The (001) in-plane shear strengths governed by plastic fiber micro-buckling failure of octet struts are given by replacing $\sigma_{\mathrm{c}}$ in Equation (15) with a conservative transverse compressive strength of the laminate material governed by plastic fiber micro-buckling failure, $\sigma_{m b}^{T}(\min )=386 \mathrm{MPa}$ (Table 1).

If we define $\sigma_{s}=\sigma_{m b}^{a v e}\left(\sigma_{m b}^{a v e}=\frac{1}{2}\left(\sigma_{m b}^{L}+\sigma_{m b}^{T}\right) \sim 535 \mathrm{MPa}\right.$, Table 1), Equation (15) can be expressed in the form of relative shear strength as

$$
\frac{\tau_{p k}}{\sigma_{s}}=\frac{\sqrt{2} t^{2}}{\sigma_{m b}^{a v e} \cos \alpha} \frac{\sigma_{c}}{A}=K_{\tau} \frac{t^{2} \sigma_{c}}{A}
$$

where $K_{\tau}$ is a constant $=\frac{\sqrt{2}}{\sigma_{m b}^{a v e} \cos \alpha}$.

\section{Discussion}

The experimentally measured shear moduli and strengths of the octet-truss lattices increased approximately linearly with lattice relative density, Table 3 . However, the manufactured samples have extra edge struts that belong to the unit cells of a larger area sample. These edge struts of partial unit cells contribute both stiffness and strength to the samples mechanical response. In order to compare experimental data and model predictions, it is therefore necessary to adjust the measured properties to account for this edge effect. If it is assumed the edge struts of adjacent cells behave in the same manner as their inner strut counterparts, the total force required to deform the counterpart lattice without redundant edge struts can be shown (by taking the ratio of the number of struts that contribute stiffness/strength 
in lattices without extra edge struts to the total number of struts in the tested samples) to be $4 / 5$ that of the lattice samples actually tested. The strength of a lattice without extra edge struts is then given by this applied force divided by its cross-sectional area, and is subsequently defined as the unit cell strength; the unit cell stiffness is obtained as this stress divided by the imposed strain. It is noted here that the manufactured samples have a height of $H(\mathrm{~s})=H+t$, where $H$ is the octahedral cell height (as shown in Fig. 5(c), $\left.H=2\left(l \sin \omega+h+2 h_{t a b}\right)\right)$.

The relative shear moduli and strengths deduced from the measurements are plotted against the relative density, $\bar{\rho}$, in Fig. 11(a) and (b). The relative moduli were obtained by normalizing the unit cell measurement by the average compressive modulus of the solid laminate, $E_{\mathrm{S}}=E_{C}^{a v e} \sim 26 \mathrm{GPa}$ and unit cell strength by plastic fiber micro-buckling failure stress, $\sigma_{\mathrm{s}}=\sigma_{m b}^{a v e}(535 \mathrm{MPa})$ of the solid laminate material. The model predictions are also plotted on the figures, and can be seen to agree well with the experimental data. The delamination and plastic fiber micro-buckling models used conservative transverse compressive strengths, $\sigma_{d l}^{T}(\min )=240 \mathrm{MPa}$ and $\sigma_{m b}^{T}(\min )=386 \mathrm{MPa}$, of the laminate material for predictions, while the average compressive modulus $E_{C}^{\text {ave }} \sim 26 \mathrm{GPa}$ was used for the elastic buckling strength predictions.

The relative shear strength is predicted to at $\bar{\rho} \approx 0.054$ to undergo a change of failure mode from elastic buckling to delamination of the compression struts. This prediction agreed well with measurements where at low densities failure occurred by elastic buckling at near $\bar{\rho}=0.054$, transitioned to the delamination mode. The plastic fiber micro-buckling failure mode for the struts was not activated (a consequence of insufficient nodal constraint), and the lattice strength never attained plastic fiber micro-buckling model predictions. 
The shear moduli and strengths of the snap-fit CFRP octet-truss lattices are compared with metal and polymer foams, balsa wood [45], several engineering alloys and recently reported titanium alloy octet-truss lattices in Fig. 12. Pyramidal and tetrahedral lattice structures were not included because their properties depend upon the core thickness and properties of the face sheets needed to achieve static determinacy [46]. The snap-fit CFRP octet-truss lattices are significantly superior to foamed structures and competitive with wrought titanium alloy octettruss lattices [32]. The snap-fit CFRP octet-truss lattices therefore provide interesting opportunities for a range of lightweight multi-functional applications that require an "open-cell" architecture. However, it is noted that the current composite lattice materials do not achieve their full lightweight potential due to the significant material that resides in the nodes.

The composite laminate used in the present study to fabricate the octet-truss lattices also has a unit price about $1 / 5$ that of wrought titanium, and required less expensive processing methods. However, the manufacture of CFRP octet-truss lattice (especially its intermediate face sheets) will generate plenty of waste material, that is more difficult to recycle or reuse. This issue could be mitigated by the use of special tooling to allow the truss pattern parts to be directly molded.

The use of snap-fit components to assemble space frames and trusses is scalable. Larger or smaller structures can be made by either simply adding or subtracting the number and/or size of components or associated layers without having to redesign or alter the component geometry. If samples of similar relative density to those reported here but with a different cell size were required, the width to length ratio of the struts should be fixed. This in turn would require a change in the thickness of the starting laminate in proportion to the change in cell length. 
The micromechanical model predictions clearly reveal the potential of CFRP octet-truss lattices for filling gaps in the material property space. They indicate that substantial improvements in experimental realizations could be achieved by increasing the elastic buckling strength by, for example, the use of composite tubes to increase the second moment of area of the struts [47]. The delamination failure of the struts could be suppressed via improved node designs, the use of a higher shear strength matrix [41] or 3D weaves/braids $[11,12,15,48,49]$. Finally, the use of nanoscopic reinforcements of the polymer matrix [50,51] might also raise the stress at which the plastic fiber micro-buckling failure mechanism is activated.

\section{Conclusions}

1. An investigation of the use of 0/90 CFRP laminate sheets to make octet-truss lattice structures has been conducted. Model CFRP octet-truss lattice structures with relative densities $(\bar{\rho})$ in the range 1.7-16\% have been successfully manufactured by employing a mechanical snap-fitting method combined with adhesive bonding.

2. The manufactured lattice structures shear moduli and strengths have been characterized under (001) in-plane shear as a function of the relative density $(\bar{\rho})$. The failure mechanism was observed to change from elastic buckling to delamination dominated failure of compression struts at a relative density of $\sim 5 \%$.

3. Analytical models for shear moduli and strengths of the snap-fit octahedral cell have been developed based on an octet-truss lattice model adapted to account for the node volume. Theoretical predictions for three representative failure modes due to elastic buckling, delamination and plastic fiber micro-buckling were derived. Good agreement between the 
measurements and the predictions was obtained including the transition from elastic buckling to delamination governed strength at a relative density near $5 \%$.

4. The structures fabricated here did not achieve the high strengths predicted by plastic fiber micro-buckling models due to an insufficient node constraint. The current design has also not optimized the node geometry and thus use material in this region has been used rather inefficiently. Nonetheless, the measured strengths and moduli exceed those of a variety of other concepts under consideration as cores of ultra-light sandwich panels.

\section{Acknowledgements}

We are grateful to the Defense Advanced Research Projects Agency for support of this work under Grant Number W91CRB-10-1-005 managed by Dr. Judah Goldwasser.

\section{References}

[1] H. G. Allen, Analysis and Design of Structural Sandwich Panels, Pergamon Press, Oxford, 1969.

[2] J. R. Vinson, "Sandwich structures", Appl. Mech. Rev. .ASME/ 54 (2001): 201-214.

[3] H. N. G. Wadley, "Multifunctional periodic cellular metals." Philosophical Transactions of the Royal Society A: Mathematical, Physical and Engineering Sciences, 364 (2006): 31-68.

[4] A.G. Evans, J.W. Hutchinson, N.A. Fleck, M.F. Ashby, and H.N.G. Wadley, "The topological design of multifunctional cellular metals." Progress in Materials Science 46 (2001): 309-327. 
[5] H.N.G. Wadley, N. A. Fleck, and A.G. Evans, "Fabrication and structural performance of periodic cellular metal sandwich structures." Composites Science and Technology 63 (2003): 2331-2343.

[6] L.J. Gibson, M.F. Ashby, 1997. Cellular Solids: Structure and Properties, 2nd Edition. Cambridge University Press, Cambridge.

[7] R. Holloman, K. Kandan, V.S. Deshpande, and H.N.G. Wadley. "Dynamic compression of square tube cellular structures." Journal of Mechanics of Materials and Structures 9 (2014): 149182.

[ 8 ] D.T. Queheillalt, and H.N.G. Wadley. "Hollow pyramidal lattice truss structures." International Journal of Materials Research 102 (2011): 389-400.

[9] H.J. Rathbun, Z. Wei, M.Y. He, F. W. Zok, A. G. Evans, D. J. Sypeck, and H. N. G. Wadley. "Measurement and simulation of the performance of a lightweight metallic sandwich structure with a tetrahedral truss core." Journal of applied mechanics 71 (2004): 368-374.

[10] K. Finnegan, G. Kooistra, H.NG Wadley, and V.S. Deshpande. "The compressive response of carbon fiber composite pyramidal truss sandwich cores." International Journal of Materials Research 98 (2007): 1264-1272.

[11] T. George, V. S. Deshpande, K. Sharp, and H.NG Wadley. "Hybrid core carbon fiber composite sandwich panels: Fabrication and mechanical response." Composite Structures 108 (2014): 696-710.

[12] T. George, V. S. Deshpande, and H.NG Wadley. "Hybrid carbon fiber composite lattice truss structures." Composites Part A: Applied Science and Manufacturing 65 (2014): 135-147. 
[13] J. Xiong, L. Ma, L. Wu, B. Wang, and A. Vaziri. "Fabrication and crushing behavior of low density carbon fiber composite pyramidal truss structures." Composite Structures 92 (2010): 2695-2702.

[14] L. Dong and H.N.G. Wadley, "Mechanical properties of carbon fiber composite octet-truss lattice structures", Composites Science and Technology, 119 (2015): 26-33.

[15] A.J. Malcom, M.T. Aronson, and H.N.G Wadley. "Three-dimensionally woven glass fiber composite struts: characterization and mechanical response in tension and compression." Journal of Composite Materials (2015): 0021998315569751.

[16] R.L. Holloman, V.S. Deshpande, H.N.G. Wadley, Impulse Transfer During Sand Impact with Cellular Structures, International Journal of Impact Engineering, 82 (2015):36-58.

[17] H.N.G. Wadley, T. Børvik, L. Olovsson, J. J. Wetzel, K. P. Dharmasena, O. S. Hopperstad, V. S. Deshpande, and J. W. Hutchinson. "Deformation and fracture of impulsively loaded sandwich panels." Journal of the Mechanics and Physics of Solids 61 (2013): 674-699.

[18] K. P. Dharmasena, D. Queheillalt, H.N.G. Wadley, Y. Chen, P. Dudt, D. Knight, Z. Wei, and A. Evans. "Dynamic response of a multilayer prismatic structure to impulsive loads incident from water." International Journal of Impact Engineering 36 (2009): 632-643.

[19] K. P. Dharmasena, H. N. G. Wadley, K. Williams, Z. Xue, and J.W. Hutchinson. "Response of metallic pyramidal lattice core sandwich panels to high intensity impulsive loading in air." International Journal of Impact Engineering 38 (2011): 275-289.

[20] J-K, Kim, and M.L. Sham, "Impact and delamination failure of woven-fabric composites." Composites Science and Technology 60 (2000): 745-761.

[21] B. Hachemane, R. Zitoune, B. Bezzazi, and C. Bouvet. "Sandwich composites impact and indentation behaviour study." Composites Part B: Engineering 51 (2013): 1-10. 
[22] V.S. Deshpande and N. A. Fleck, "Collapse of truss core sandwich beams in 3-point bending", Int. J. Solids Struct. 38 (2001): 6275-6305

[23] A.G. Evans, J. W. Hutchinson, and M. F. Ashby. "Multifunctionality of cellular metal systems." Progress in Materials Science 43 (1998): 171-221.

[24] T. George, V. S. Deshpande, and H.N.G Wadley. "Mechanical response of carbon fiber composite sandwich panels with pyramidal truss cores." Composites Part A: Applied Science and Manufacturing 47 (2013): 31-40.

[25] D.T. Queheillalt, D. T., Y. Murty, and H. N.G Wadley. "Mechanical properties of an extruded pyramidal lattice truss sandwich structure." Scripta Materialia 58 (2008): 76-79.

[26] D.T. Queheillalt, and H.N.G Wadley. "Titanium alloy lattice truss structures." Materials \& Design, 30 (2009): 1966-1975.

[27] N. Wicks, and J. W. Hutchinson. "Optimal truss plates." International Journal of Solids and Structures 38(2001): 5165-5183.

[28] S. Chiras, D. R. Mumm, A. G. Evans, N. Wicks, J. W. Hutchinson, K. Dharmasena, H. N. G. Wadley, and S. Fichter. "The structural performance of near-optimized truss core panels." International Journal of Solids and Structures 39(2002): 4093-4115.

[29] S.M. Pingle, N.A. Fleck, V.S. Deshpande, H.N.G. Wadley, Collapse mechanism maps of hollow pyramidal lattice. Proc. Roy. Soc. Lond. A 467 (2010): 985-1011.

[30] S.M. Pingle, N.A. Fleck, V.S. Deshpande, H.N.G. Wadley, Collapse Mechanism Maps for the Hollow Pyramidal Core of a Sandwich Panel Under Transverse Shear, International Journal of Solids and Structures, 48 (2011): 3417-3430.

[31] R.B. Fuller, 1961. Octet truss. U.S. Patent Serial No. 2, 986, 241. 
[32] V.S. Deshpande, N. A. Fleck, and M. F. Ashby. "Effective properties of the octet-truss lattice material." Journal of the Mechanics and Physics of Solids 49 (2001): 1747-1769.

[33] D.W. Rosen, "Computer-aided design for additive manufacturing of cellular structures." Computer-Aided Design and Applications 4 (2007): 585-594.

[34] J.S. Chu, S. Engelbrecht, G. Graf, and D. W. Rosen. "A comparison of synthesis methods for cellular structures with application to additive manufacturing." Rapid Prototyping Journal 16 (2010): 275-283.

[35] C.B. Williams, K.C. Joe, and D.W. Rosen. "Additive manufacturing of metallic cellular materials via three-dimensional printing." The International Journal of Advanced Manufacturing Technology 53 (2011): 231-239.

[36] L. Dong, V.S. Deshpande, and H.N.G. Wadley. "Mechanical response of Ti-6Al-4V octettruss lattice structures." International Journal of Solids and Structures 60 (2015): 107-124.

[37] N.A. Fleck, P. M. Jelf, and P. T. Curtis. "Compressive failure of laminated and woven composites." Journal of composites technology \& research 17 (1995): 212-220.

[38] L. Wang, "Effects of in-plane fiber waviness on the static and fatigue strength of fiberglass." PhD diss., Montana State University-Bozeman, 2001.

[39] D.P. Avery, D.S. Daniel, J. F. Mandell, and D.S. Cairns. "Compression strength of carbon fiber laminates containing flaws with fiber waviness." In Proceedings of the 42nd AIAA Aerospace Sciences Meeting and Exhibit, pp. 54-63. 2004.

[40] S.T. Pinho, R. Gutkin, S. Pimenta, N.V.De Carvalho, and P. Robinson. "On longitudinal compressive failure of carbon-fibre-reinforced polymer: from unidirectional to woven, and from virgin to recycled." Philosophical Transactions of the Royal Society A: Mathematical, Physical and Engineering Sciences 370 (2012): 1871-1895. 
[41] B.D. Garland, I. J. Beyerlein., and L. S. Schadler. "The development of compression damage zones in fibrous composites." Composites science and technology 61 (2001): 2461-2480. [42]https://tds.us.henkel.com/NA/UT/HNAUTTDS.nsf/web/8FD3ABAA09A649FE8825718700 00DB2F/\$File/EA\%20E-120HP-EN.pdf.

[ 43 ] D.F.Adams, "Shear testing of sandwich panel core materials", High-Performance Composites, 15(2007): 8-9.

[44] N.A. Fleck, "Compressive failure of fiber composites." Advances in applied mechanics 33 (1997): 43-117.

[ 45 ] A.D.Silva, and S.Kyriakides. "Compressive response and failure of balsa wood." International Journal of Solids and Structures 44 (2007): 8685-8717.

[46] S. Pellegrino, and C. R. Calladine. "Matrix analysis of statically and kinematically indeterminate frameworks." International Journal of Solids and Structures 22 (1986): 409-28.

[47] S. Yin, L.Z. Wu, L. Ma, and S. Nutt. "Pyramidal lattice sandwich structures with hollow composite trusses." Composite Structures 93 (2011): 3104-3111.

[48] A.J. Malcom, M. T. Aronson, and H.N.G. Wadley. "Three-dimensionally woven glass fiber composite struts: characterization and mechanical response in tension and compression." Journal of Composite Materials (2015): 0021998315569751.

[49] K. Dransfield, C. Baillie, and Y.W. Mai. "Improving the delamination resistance of CFRP by stitching_a review." Composites Science and Technology 50 (1994): 305-317.

[50] V.P. Veedu, A. Cao, X. Li, K. Ma, C. Soldano, S. Kar, P. M. Ajayan, and M. N. GhasemiNejhad. "Multifunctional composites using reinforced laminate with carbon-nanotube forests." Nature materials, 5 (2006): 457-462. 
[51] S.S. Wicks, R. Guzman de Villoria, and B. L. Wardle. "Interlaminar and intralaminar reinforcement of composite laminates with aligned carbon nanotubes." Composites Science and Technology, 70 (2010): 20-28.

Figure 1. (a) An octet-truss lattice constructed by the 3D translation of the unit cell shown in (b). The unit cell of the octet-truss lattice is composed of a (red) center octahedral unit and 8 (blue) edge tetrahedral cells.

Figure 2. Schematic illustration of the internal structure of the as-received CFRP laminate used to make the lattice. The laminate comprised 2 surface plies made from plain weave fabrics that sandwich 6 unidirectional plies of the same thickness arranged as a [0/90/0]s layup.

Figure 3. (a) Example of delamination dominated failure during unclamped compression. (b) Plastic fiber micro-buckling failure during CLC compression. Higher resolution $\mu$-XCT images of the laminate showing the failure modes after (c) unclamped compression and (d) CLC compression are also shown.

Figure 4. Schematic illustration of the "snap-fit" truss fabrication and assembly method for making an octet-truss lattice from the 0/90 CFRP laminate sheets.

Figure 5. The geometries of (a) pyramidal truss and (b) intermediate face with relevant core design variables identified. (c) A sketch of an octahedral cell with a Cartesian co-ordinate system and miller index loading directions.

Figure 6. (a) Photograph of a snap-fit CFRP octet-truss shear test structure $(\bar{\rho}=5.4 \%)$. The photographs in (b) and (c) show the assembly stages and also illustrate the internal truss structures. The sample size was defined by length $L(\mathrm{~s})$, width $W(\mathrm{~s})$, and height $H(\mathrm{~s})$. 
Figure 7. Sketch of the single lap compression plate setup used to measure the shear response of the octet-truss shear samples. The dash loading line represents the line of action along which the compression load was applied.

Figure 8. (001) in-plane shear stress-strain responses of the snap-fit CFRP octet-truss shear samples with various relative densities.

Figure 9. (a) Photograph of a snap-fit CFRP octet-truss shear sample $(\bar{\rho}=5.4 \%)$ just after attainment of the shear strength. (b) A close-up view of the delaminated and shear failed struts.

Figure 10. (a) The octahedral cell with a pyramidal strut and loading directions identified. Free body diagram for such a strut showing the combination of axial and shear forces present when the unit cell is under (b) (001) in-plane shear.

Figure 11. Comparisons between measured (symbols) and predicted (001) in-plane relative shear moduli (a) and strengths (b) of the snap-fit CFRP octahedral cells as a function of the relative density. Error bars represent the maximum and minimum values obtained from 3 separate measurements.

Figure 12. Material property charts showing (a) the shear modulus and (b) the shear strength experimental data (unit cell response, Table 3) and model predictions for the snap-fit CFRP octet-truss lattices investigated here. The experimental data and model predictions for the Ti6Al-4V octet-truss lattices and the shear properties of polymer and metal foams and several solid materials are also shown for comparison. 
Table 1: The measured properties of the as-received CFRP laminate along both the longitudinal and transverse directions. Standard deviations are given based on multiple measurements for each mechanical property.

\begin{tabular}{c|cccccc}
\hline \hline & $\begin{array}{c}\text { Compressive } \\
\text { modulus } \\
\text { (Unclamped) }\end{array}$ & $\begin{array}{c}\text { Compressive } \\
\text { modulus }(\mathrm{CLC})\end{array}$ & $\begin{array}{c}\text { Micro- } \\
\text { buckling } \\
\text { strength } \\
(\mathrm{CLC})\end{array}$ & $\begin{array}{c}\text { Delamination } \\
\text { strength } \\
\text { (Unclamped) }\end{array}$ & $\begin{array}{c}\text { Tensile } \\
\text { strength }\end{array}$ & $\begin{array}{c}\text { Tensile } \\
\text { modulus }\end{array}$ \\
& $E_{C(U C)}(\mathrm{GPa})$ & $E_{C(C L C)}(\mathrm{GPa})$ & $\sigma_{m b}$ & $\sigma_{d l}$ & $\sigma_{T}$ & $E_{T}$ \\
& & & $(\mathrm{MPa})$ & $(\mathrm{MPa})$ & $(\mathrm{MPa})$ & $(\mathrm{GPa})$ \\
\hline $\begin{array}{c}\text { Longitudinal } \\
\text { direction }(L)\end{array}$ & $32.5 \pm 1.8$ & $33.6 \pm 2.1$ & $640 \pm 36$ & $457 \pm 76$ & $949 \pm 34$ & $76 \pm 3.5$ \\
\hline $\begin{array}{c}\text { Transverse } \\
\text { direction }(T)\end{array}$ & $19.8 \pm 2.3$ & $20.5 \pm 1.4$ & $428 \pm 42$ & $305 \pm 63$ & $497 \pm 10$ & $45 \pm 1.9$ \\
& $(15$ tests $)$ & $(7$ tests $)$ & $(6$ tests $)$ & $(28$ tests $)$ & $(5$ tests $)$ & $(5$ tests $)$ \\
\hline
\end{tabular}

Table 2: Node and strut dimensions for the snap-fit CFRP octet-truss lattices manufactured in this study (unit: $\mathrm{mm}$ ).

\begin{tabular}{cccccccccc}
\hline \hline$t$ & $w$ & $b$ & $c$ & $h$ & $h_{\text {tab }}$ & $\omega$ & $t_{0}$ & $m$ & $R$ \\
\hline 1.588 & 1.588 & 4.763 & 2.235 & 0.953 & 1.588 & $45^{\circ}$ & 1.270 & 2.769 & 5.080
\end{tabular}


Table 3: Relative densities, experimental and unit cell (001) in-plane shear moduli and shear strengths of the manufactured snap-fit CFRP octet-truss shear specimens.

\begin{tabular}{|c|c|c|c|c|c|}
\hline $\begin{array}{l}\text { Length } \\
(l, \mathrm{~mm})\end{array}$ & $\begin{array}{c}\text { Relative } \\
\text { density } \\
(\bar{\rho})\end{array}$ & $\begin{array}{c}\text { Sample } \\
\text { Shear stiffness } \\
(\mathrm{GPa})\end{array}$ & $\begin{array}{c}\text { Unit cell } \\
\text { shear stiffness } \\
(\mathrm{GPa})\end{array}$ & $\begin{array}{c}\text { Sample } \\
\text { Shear strength } \\
(\mathrm{MPa})\end{array}$ & $\begin{array}{c}\text { Unit cell } \\
\text { shear strength } \\
(\mathrm{MPa})\end{array}$ \\
\hline 33.020 & $1.7 \%$ & 0.066 & 0.052 & 0.46 & 0.38 \\
\hline 16.891 & $5.4 \%$ & 0.157 & 0.125 & 2.21 & 1.84 \\
\hline 12.014 & $9.4 \%$ & 0.282 & 0.222 & 3.47 & 2.92 \\
\hline 9.728 & $13.0 \%$ & 0.424 & 0.332 & 4.45 & 3.77 \\
\hline 8.433 & $15.9 \%$ & 0.493 & 0.387 & 5.91 & 5.03 \\
\hline
\end{tabular}


(a) Octet-truss lattice

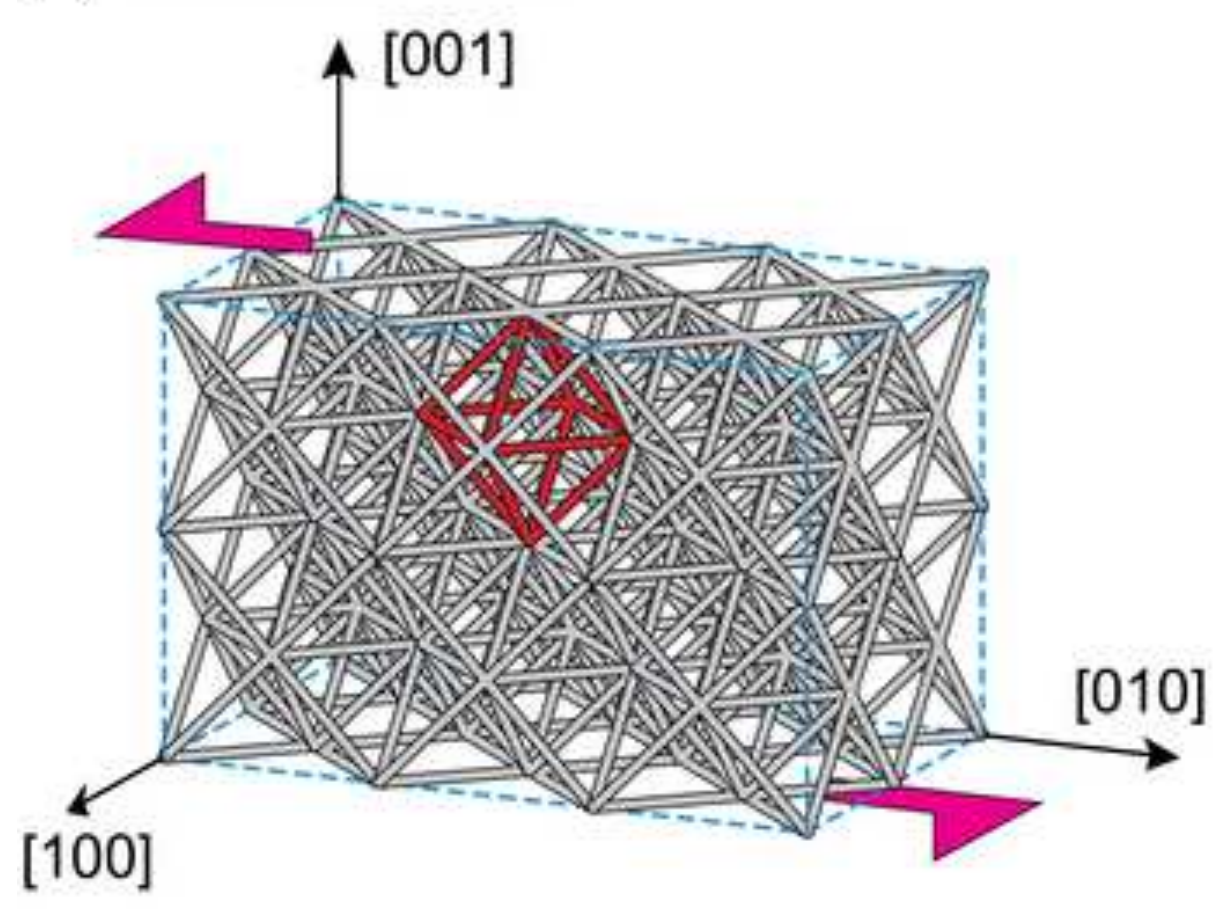

(b) Unit cell

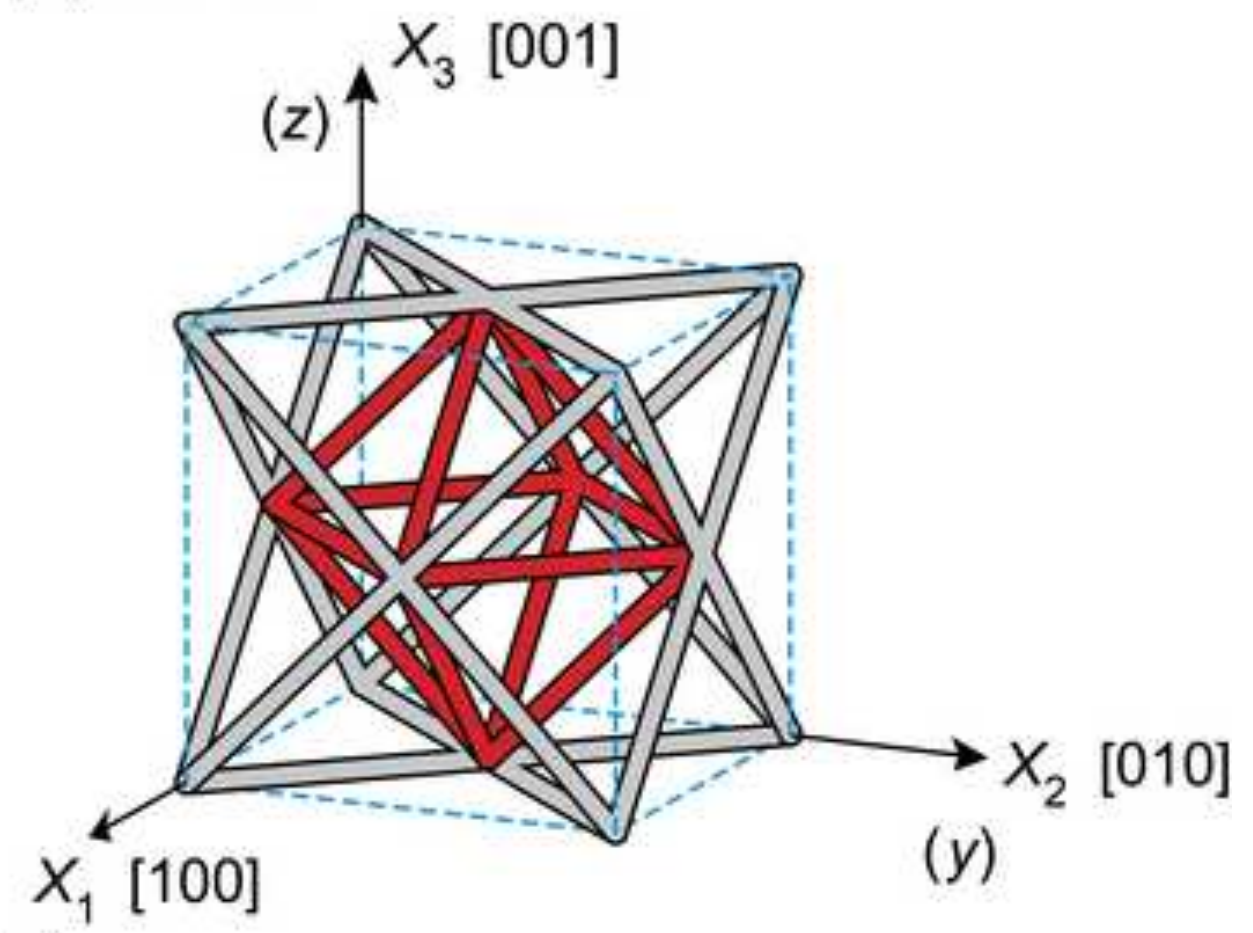

(x) 
Click here to download high resolution image

FIG 2
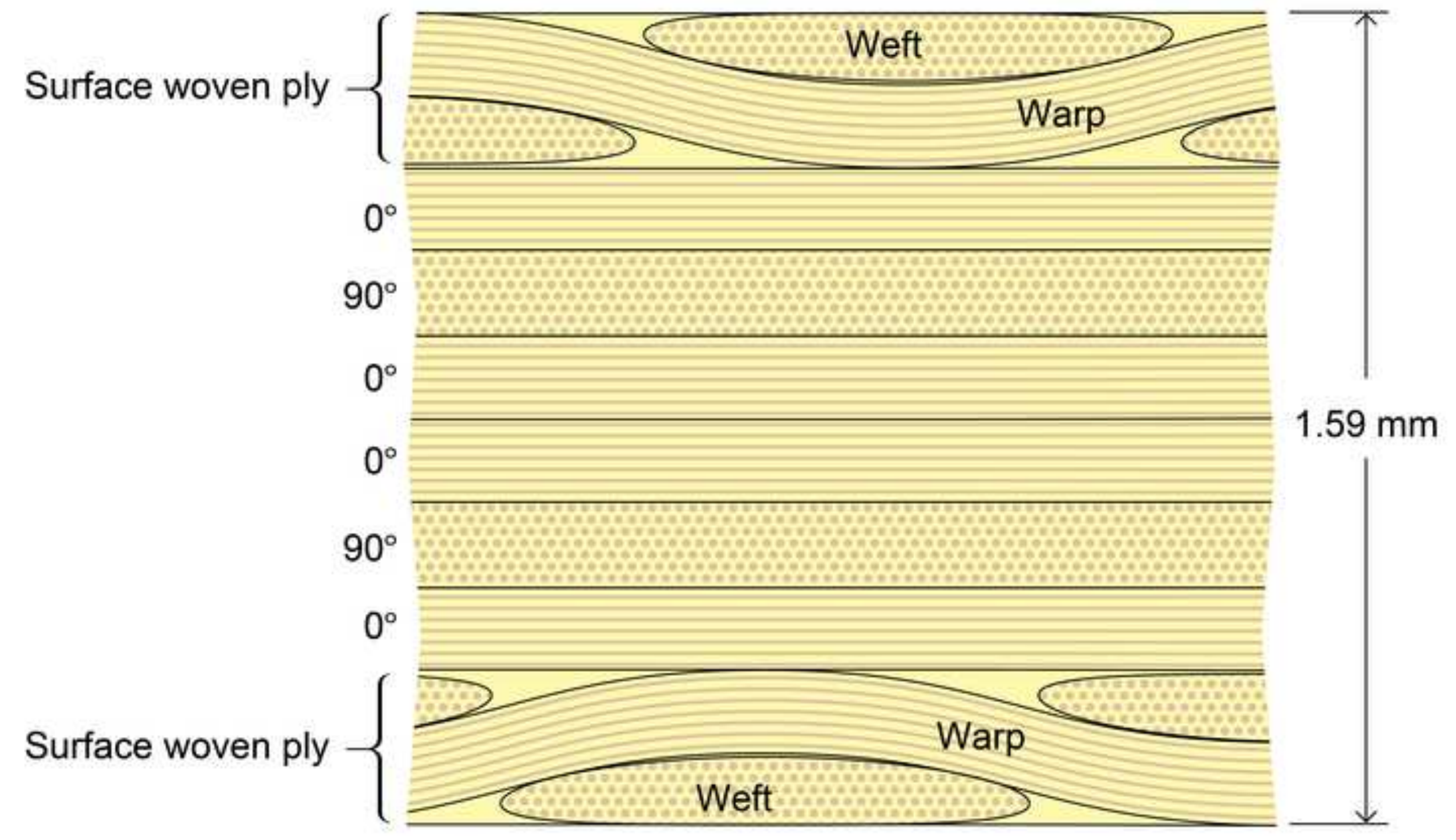


\section{Figure(s)}

Click here to download high resolution image

FIG 3
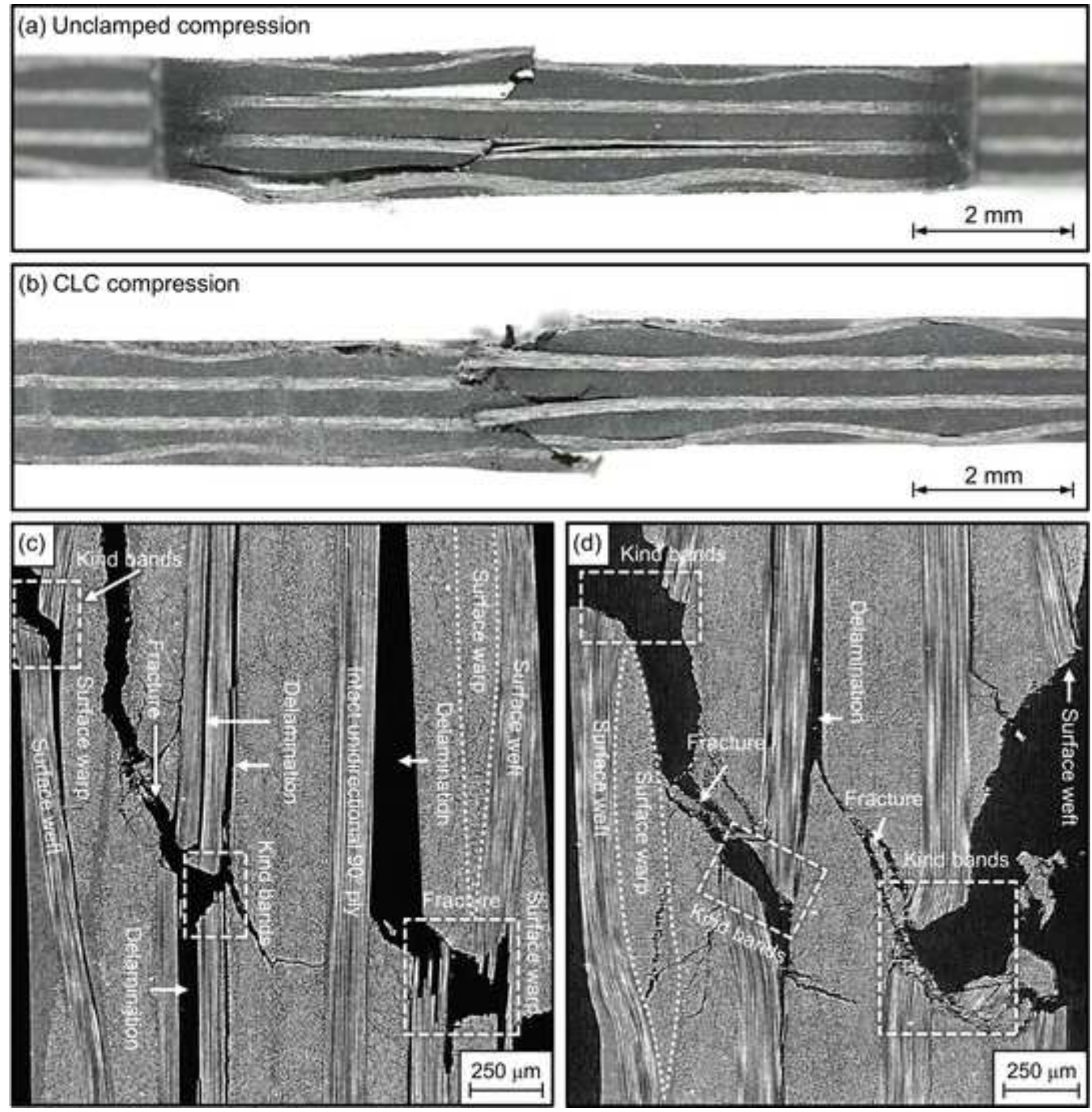
(a) Pyramidal trusses fabrication

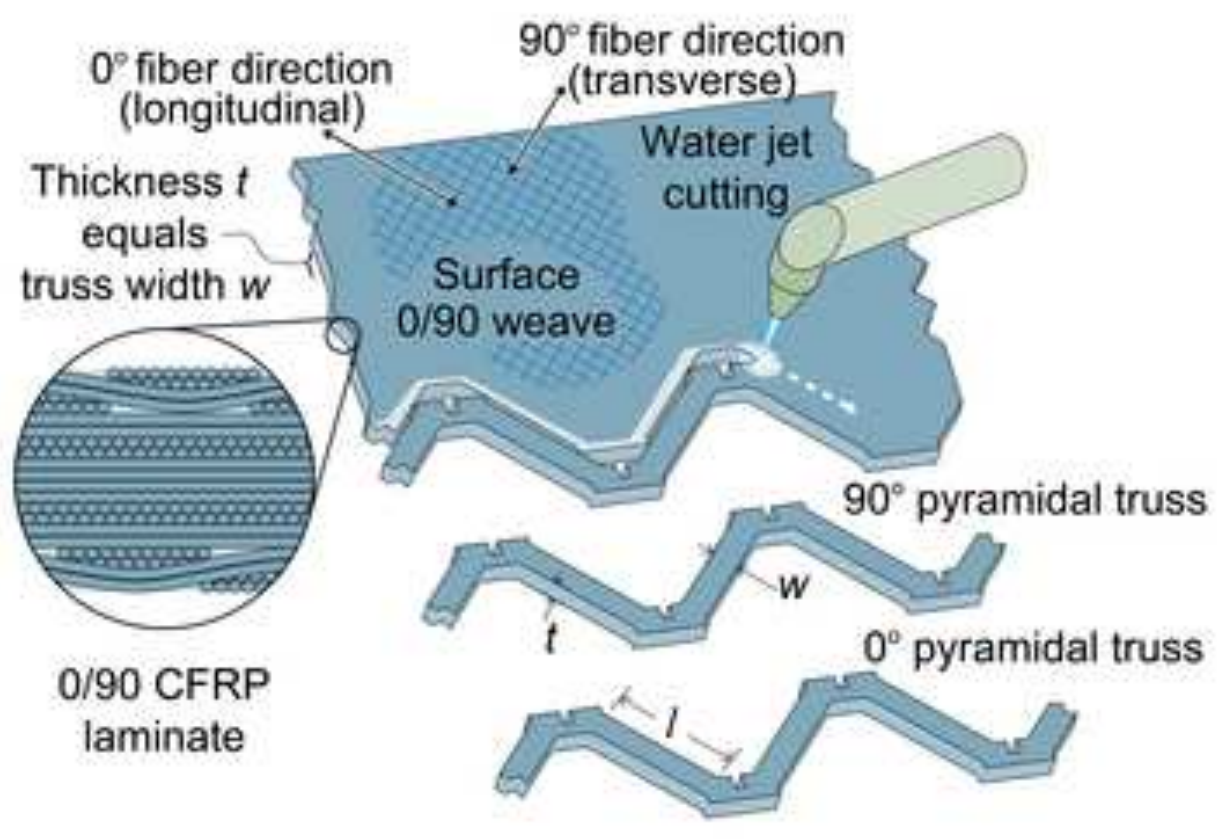

(b) Intermediate face fabrication

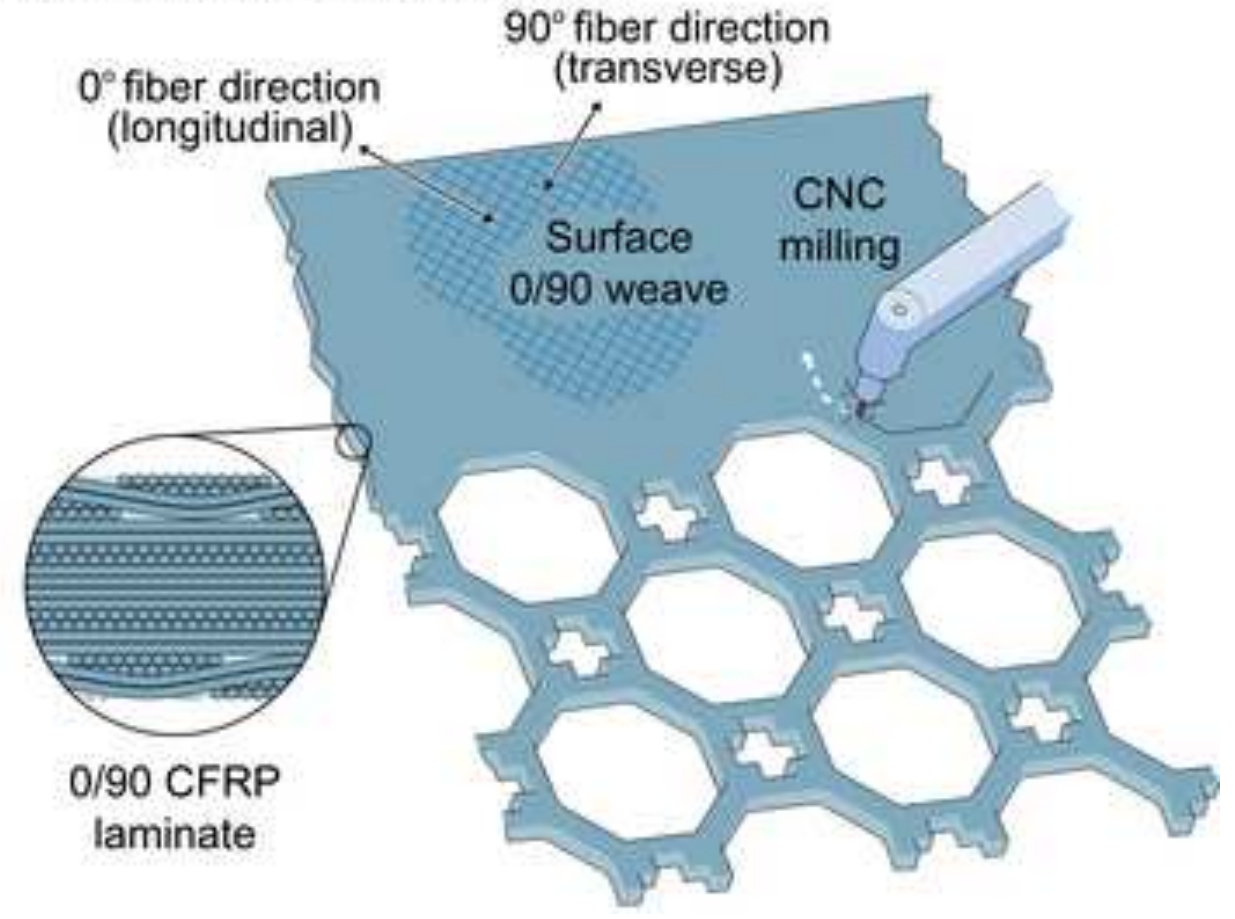



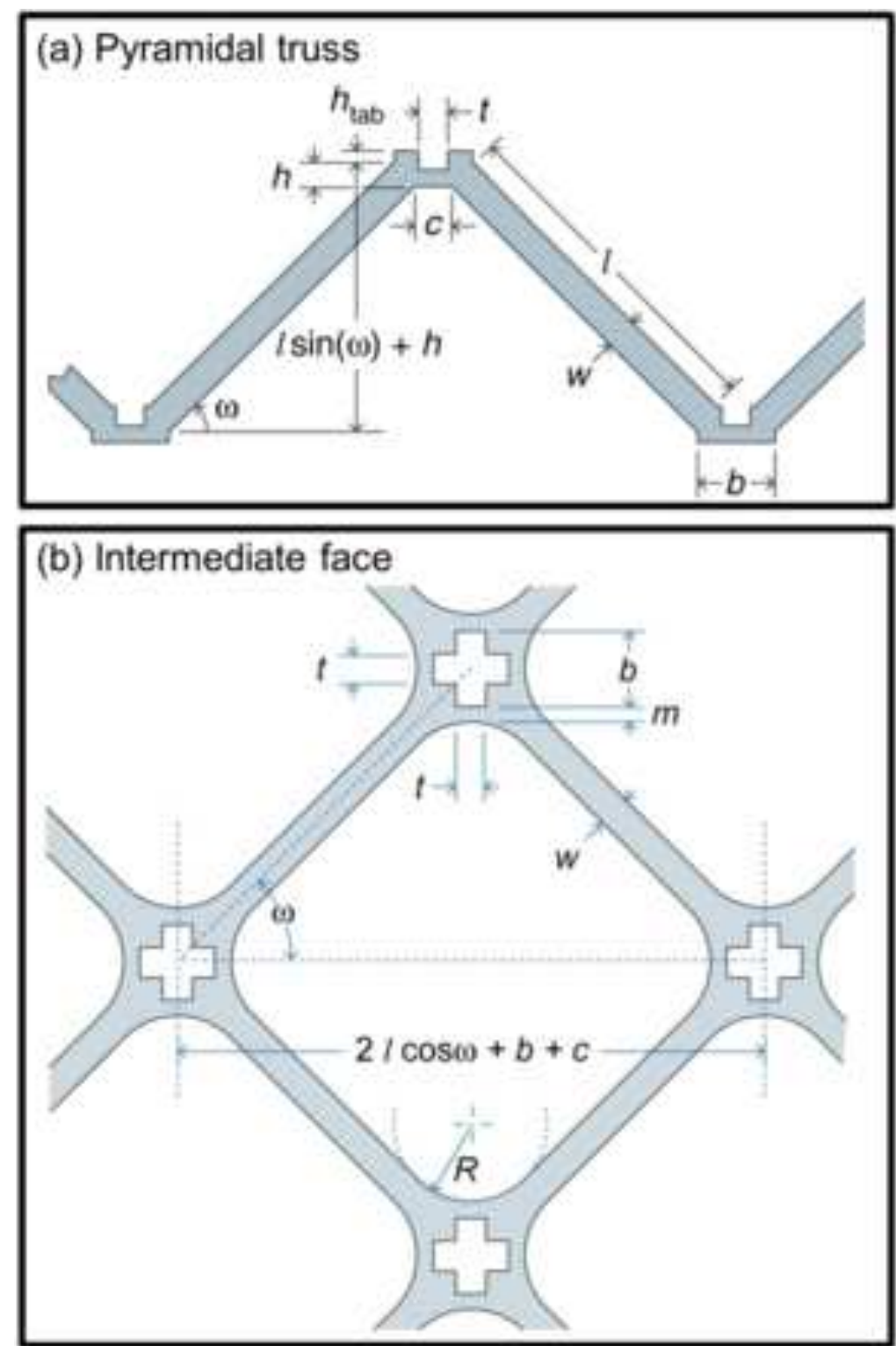

(c) Unit cell

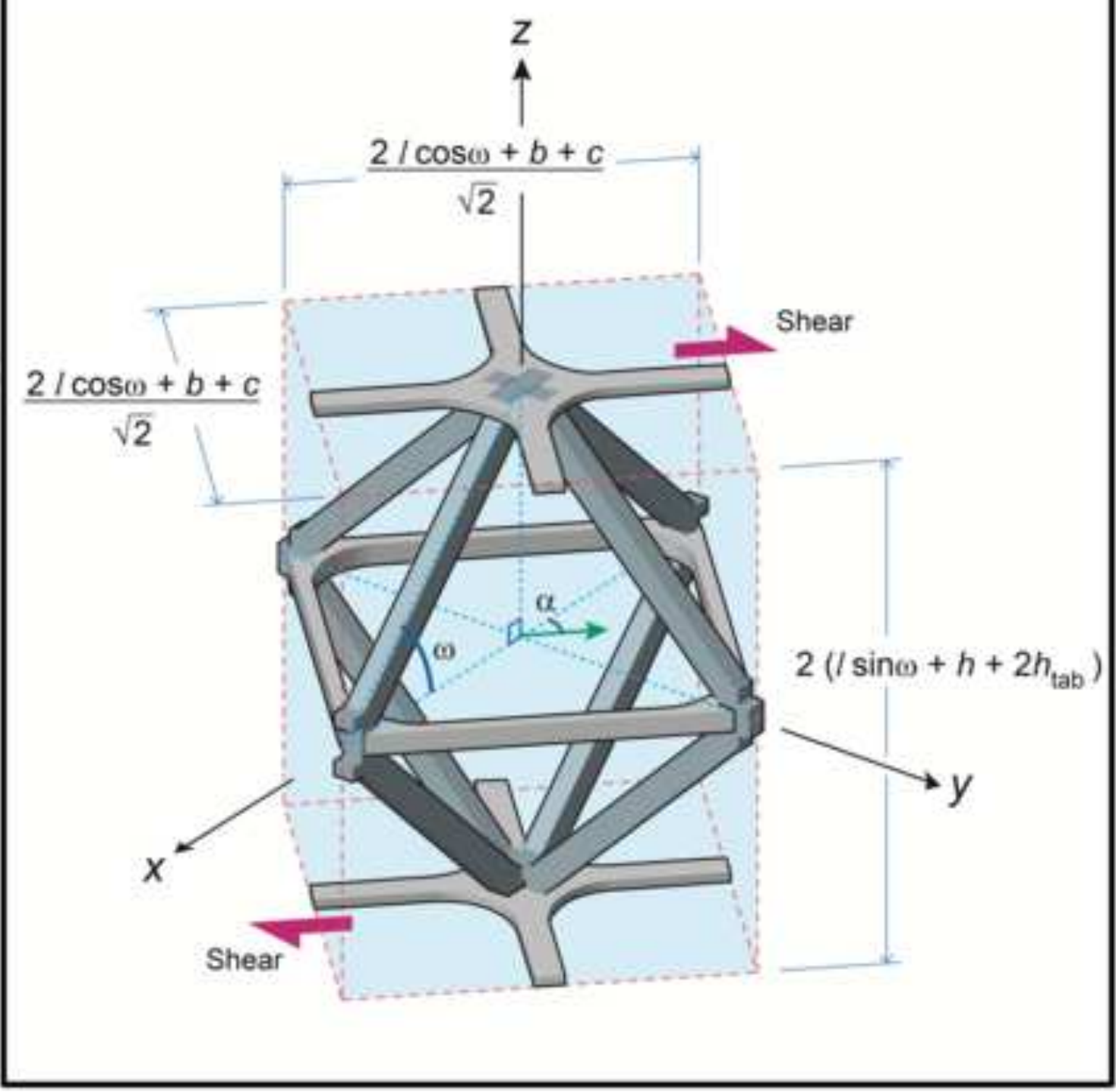




\section{Figure(s)}

Click here to download high resolution image

FIG 6

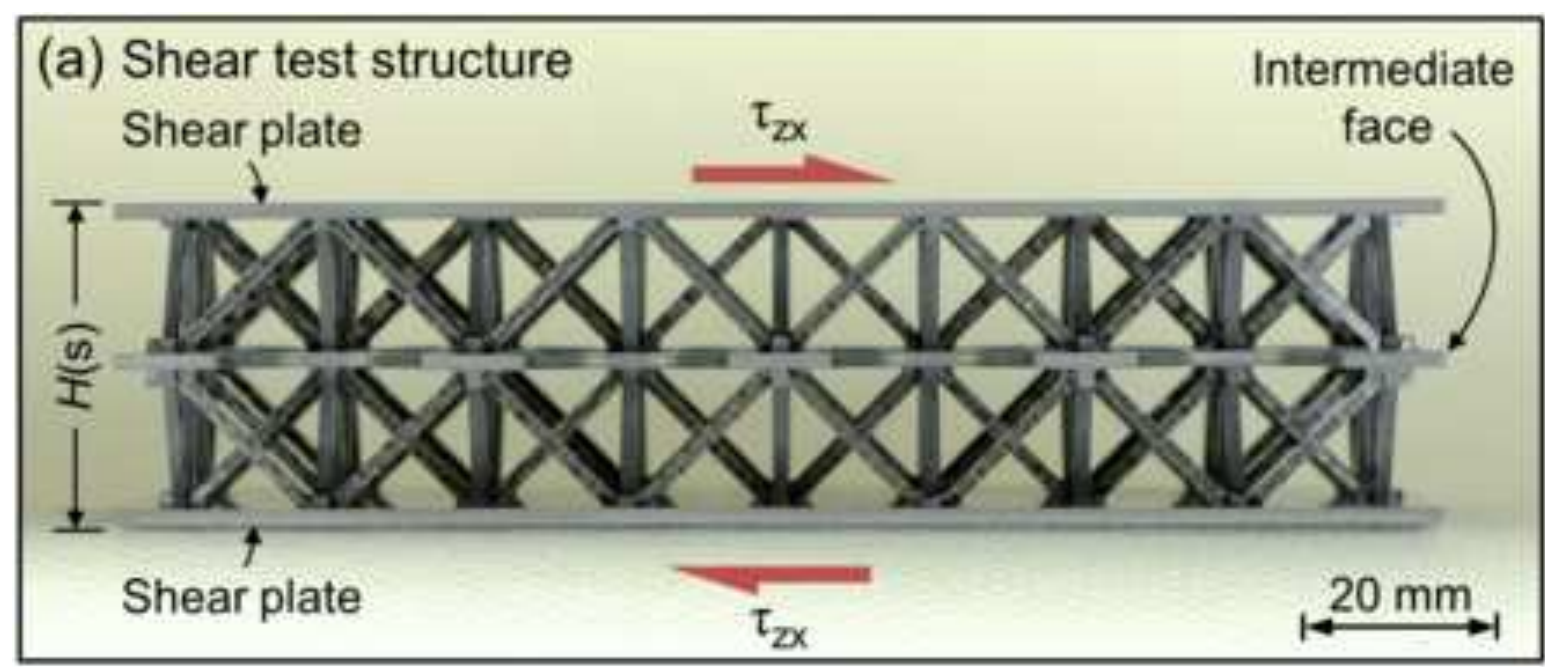

(b) Lower shear plate + pyramidal trusses
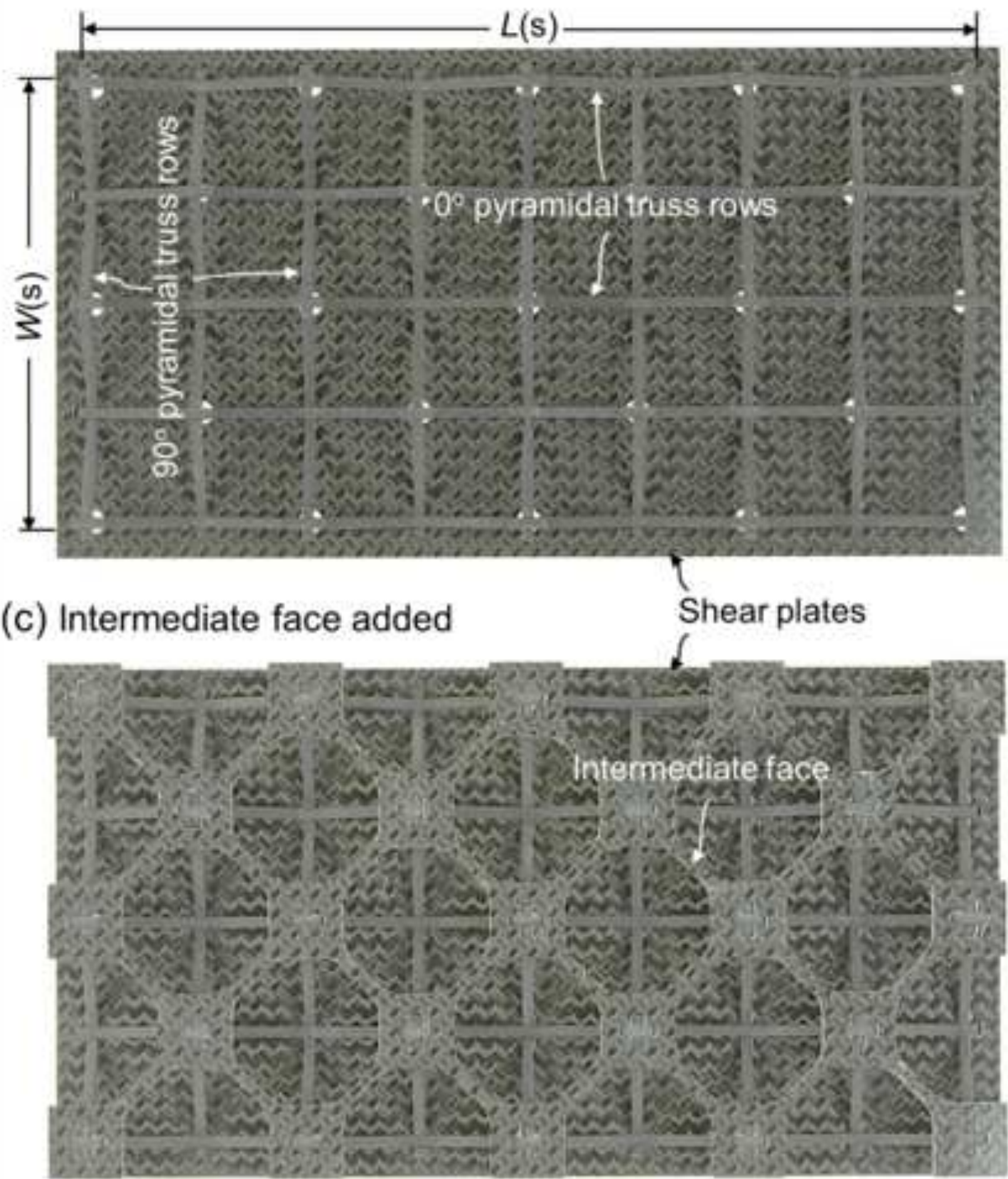
FIG 7

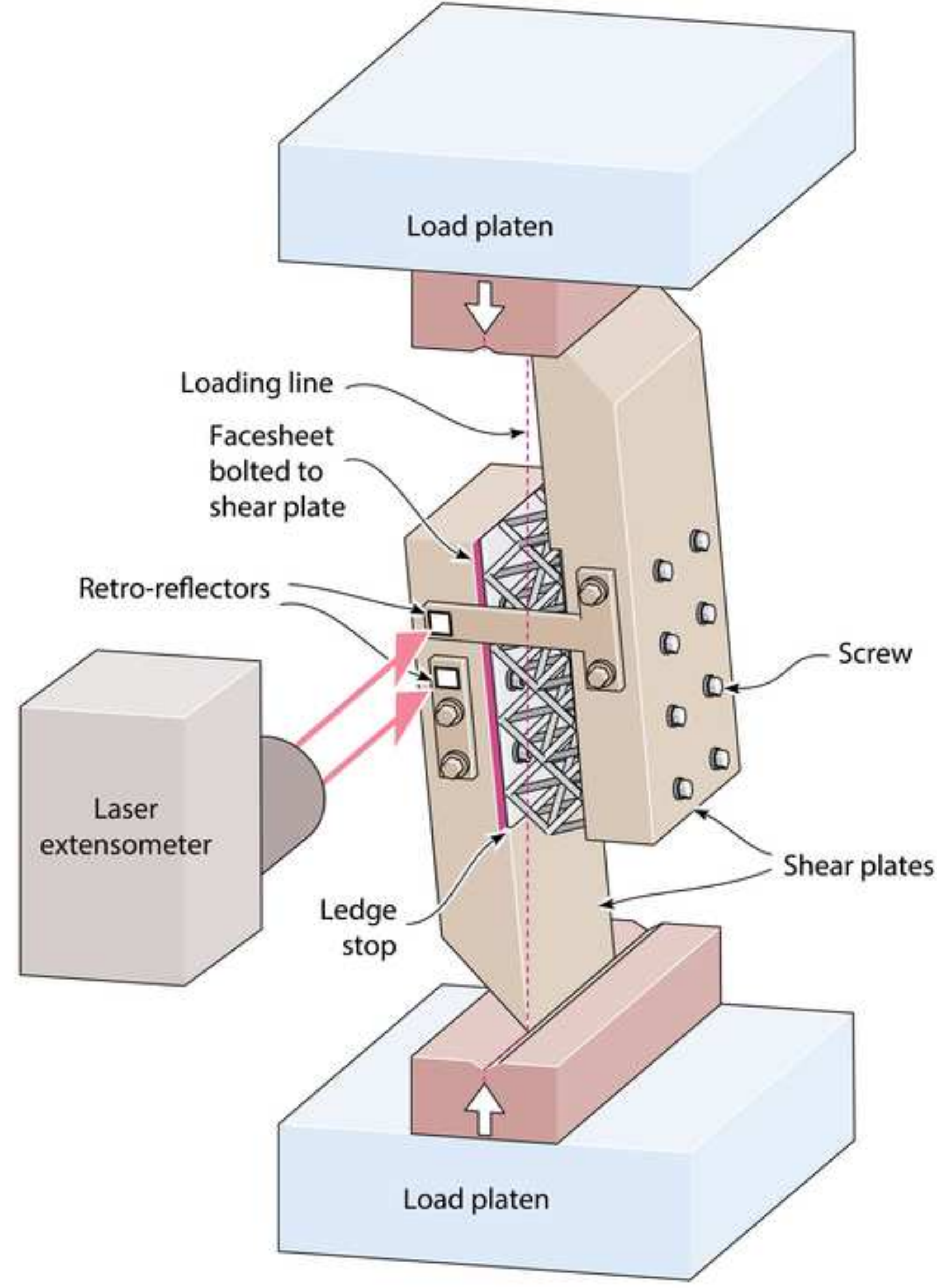


Click here to download high resolution image

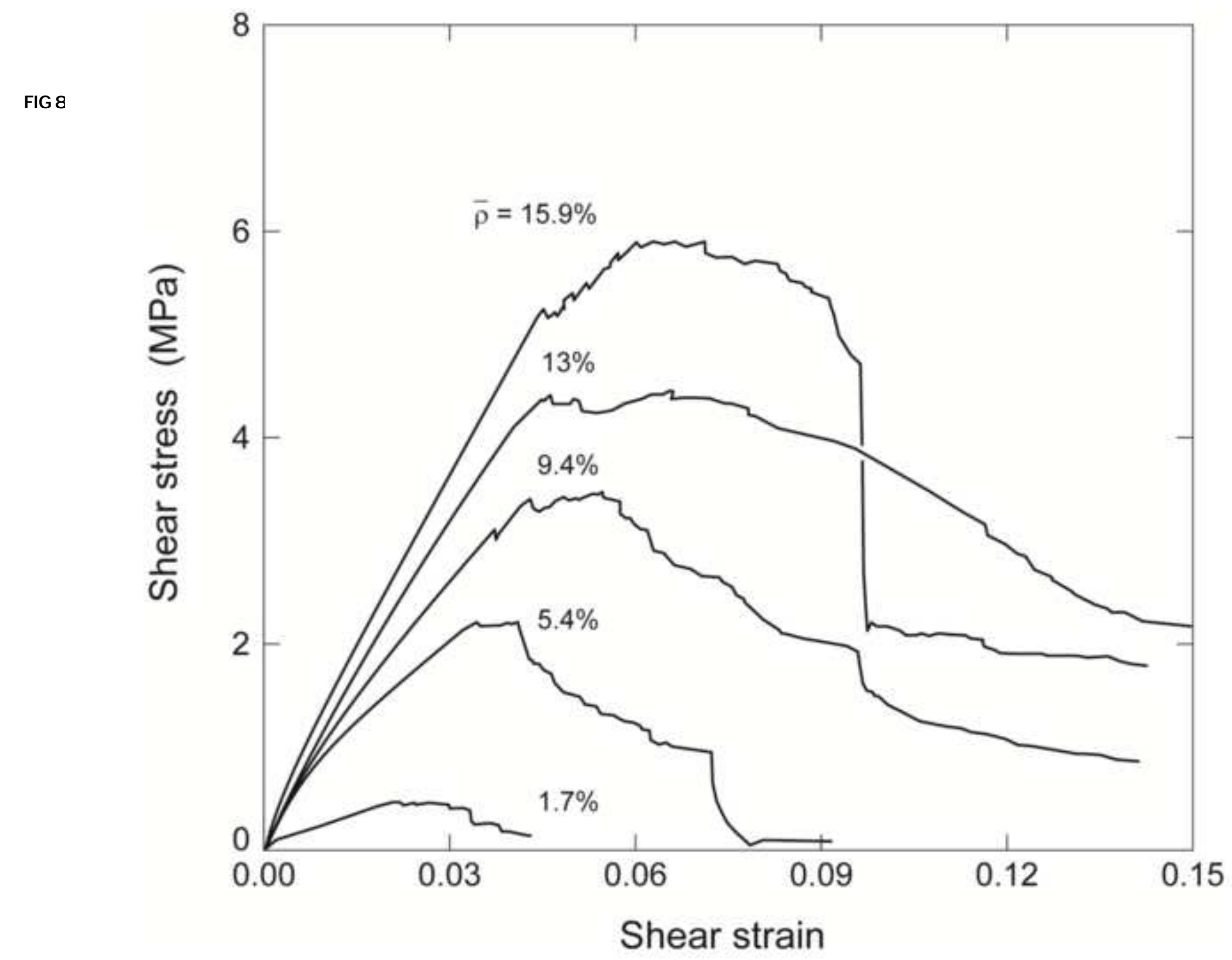


Click here to download high resolution image
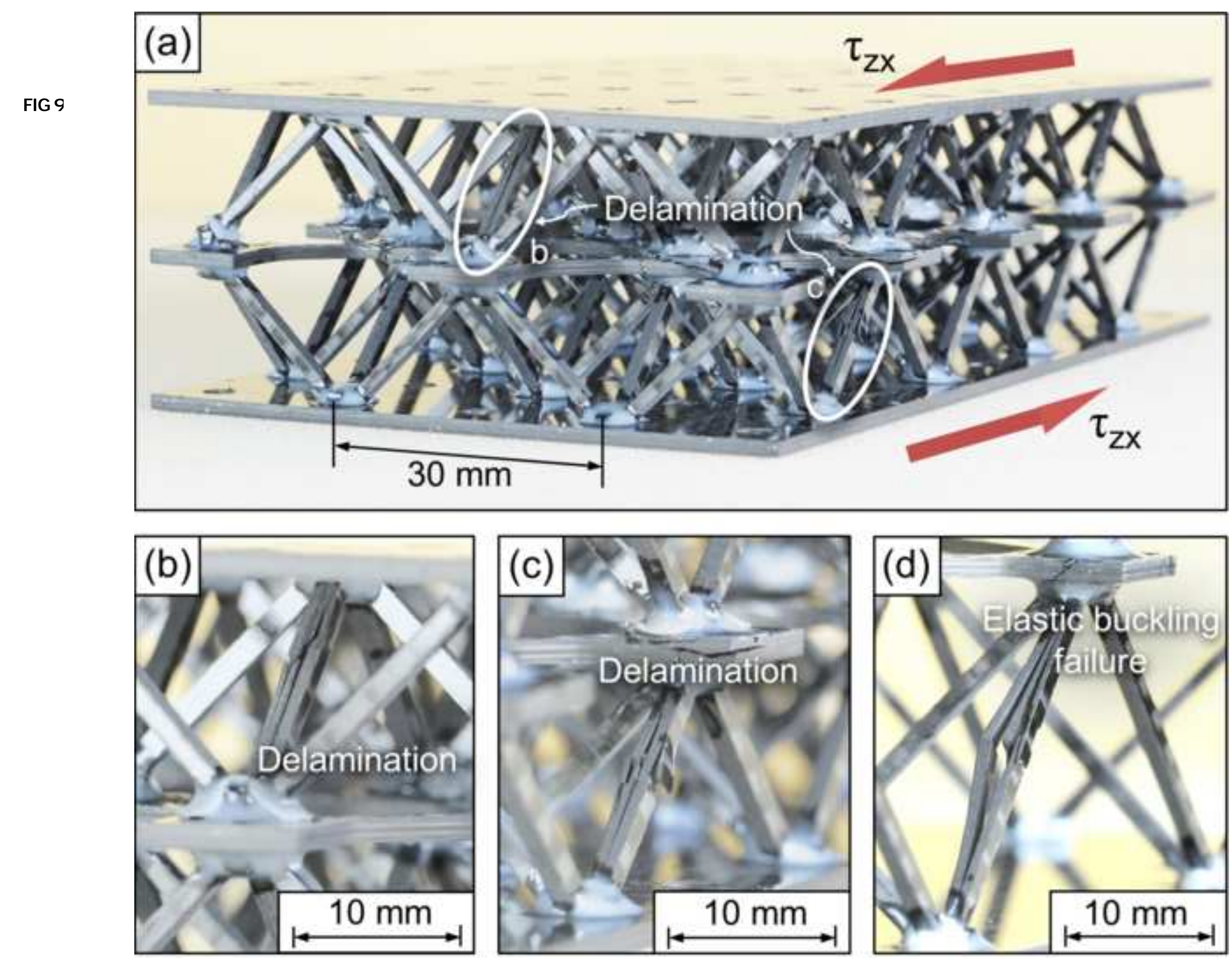
FIG 10

(a) Unit cell

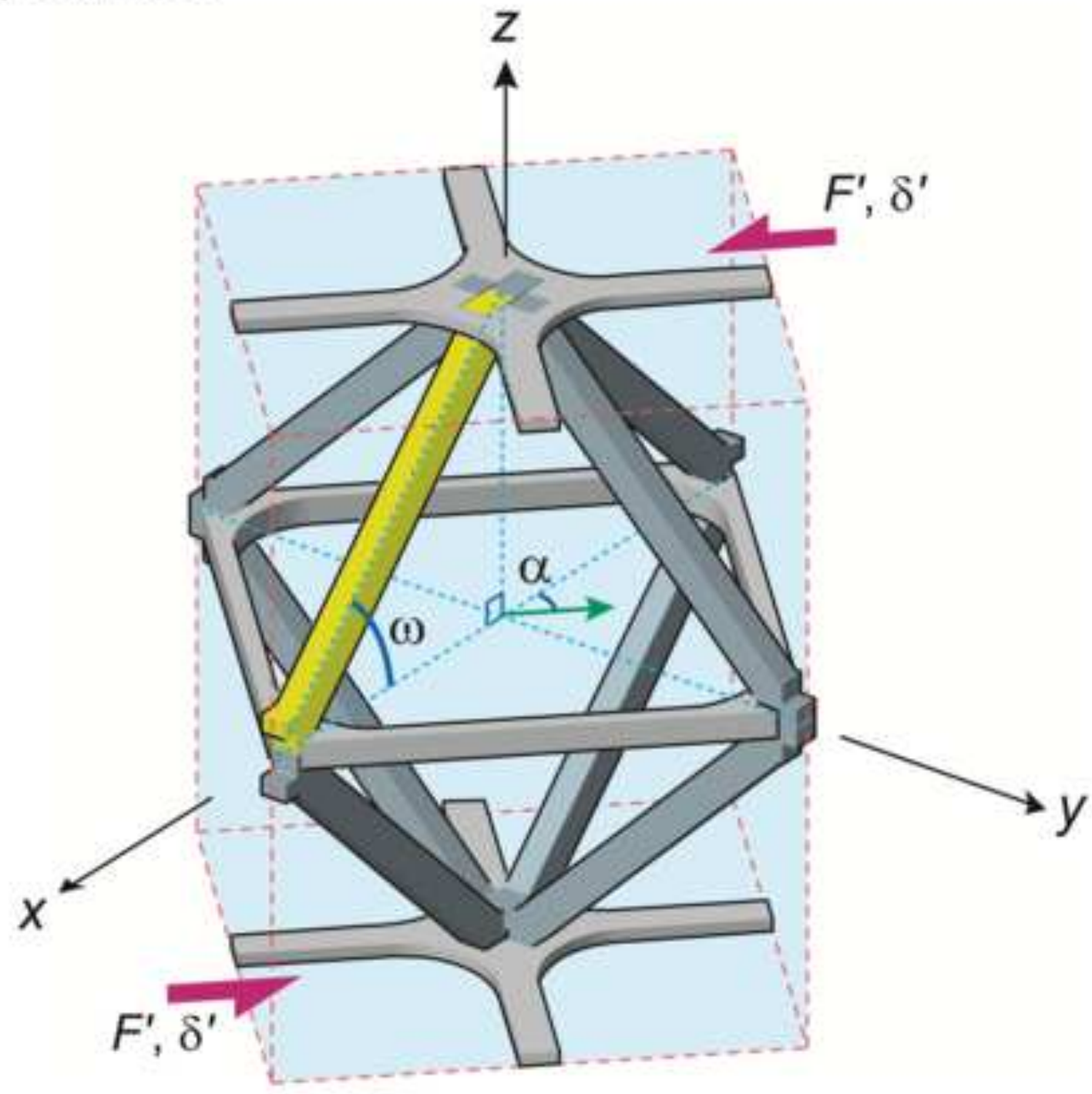

(b) Shear

$$
\begin{aligned}
& \delta^{\prime} \cos \alpha \cos \omega \\
& \text { or } \\
& \delta^{\prime} \sin \alpha \cos \omega
\end{aligned}
$$

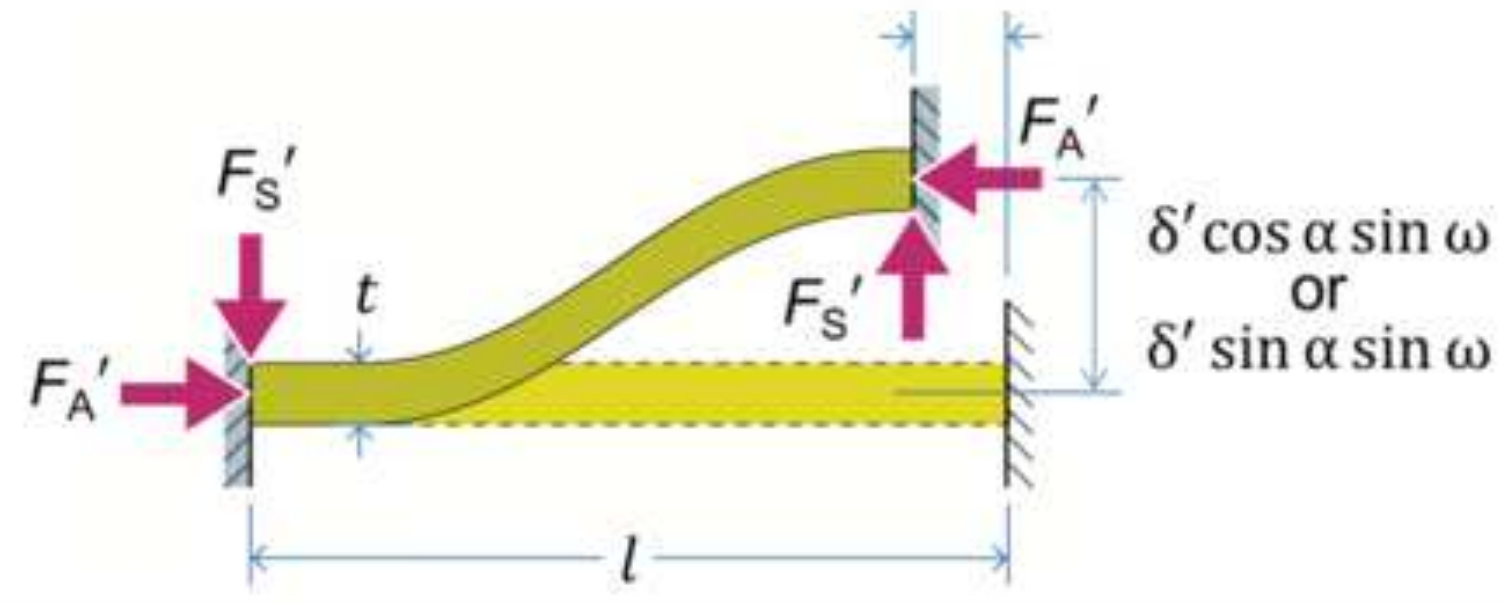




\section{Figure(s)}

Click here to download high resolution image
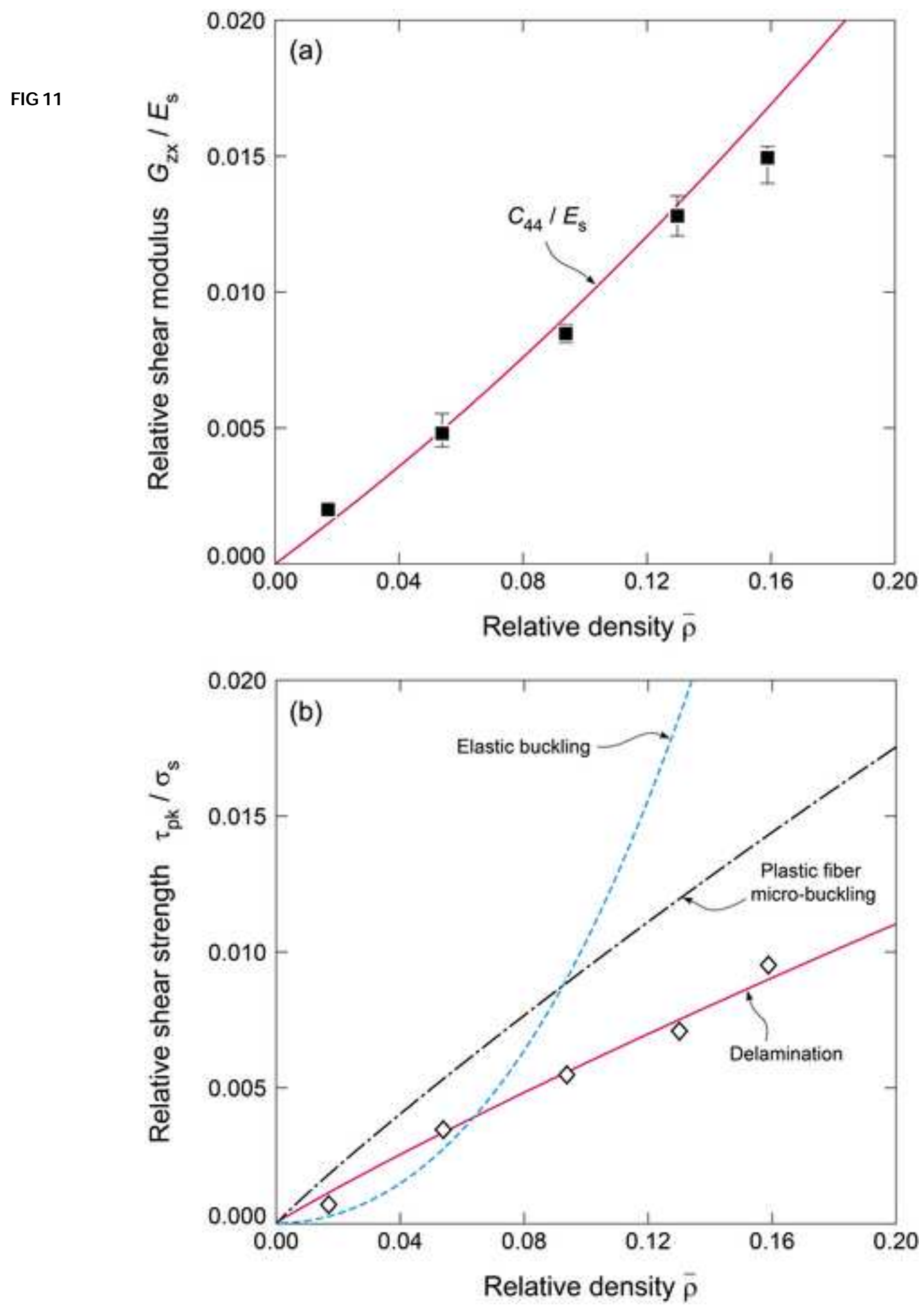
FIG 12
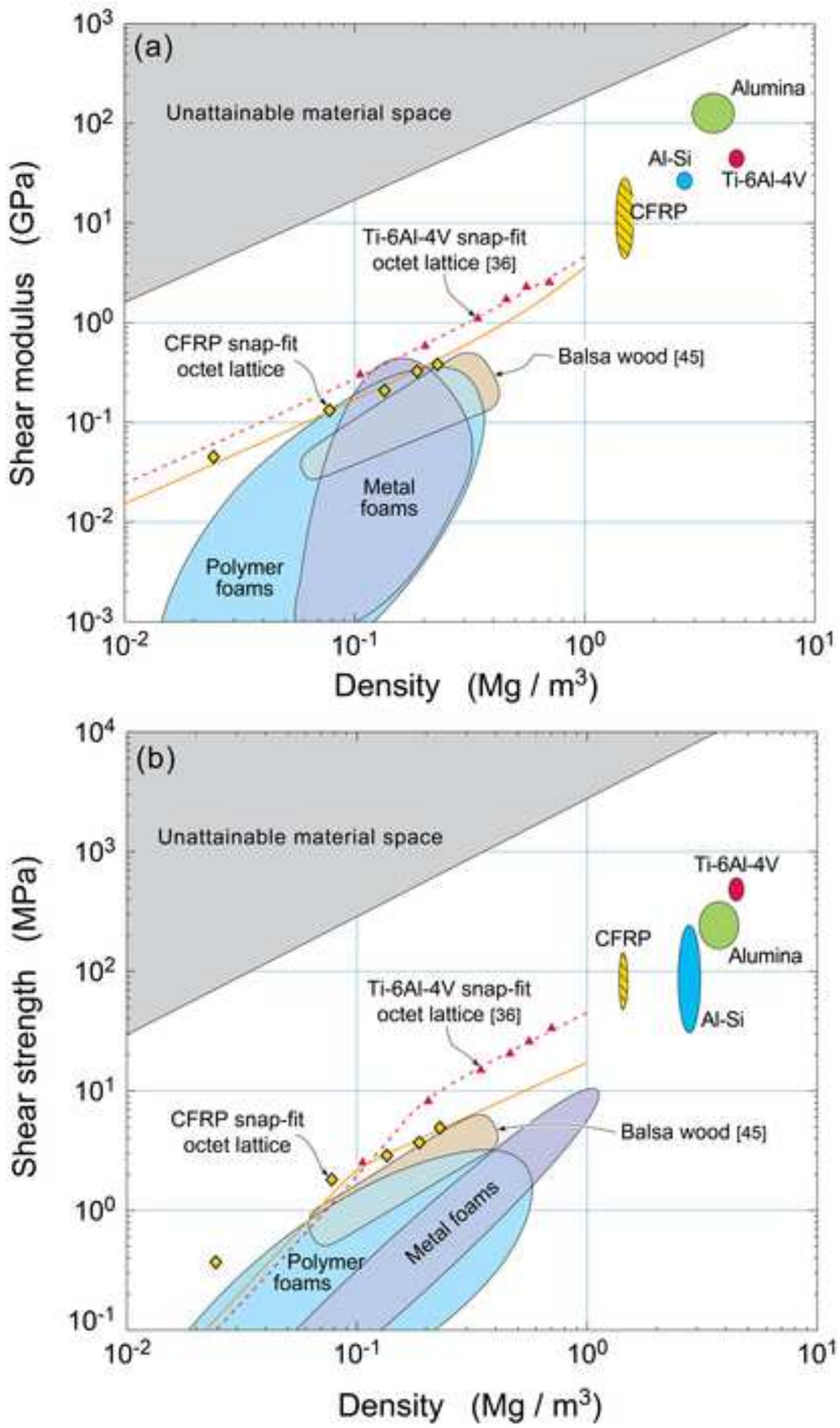